Check for updates

Cite this: RSC Med. Chem., 2020, 11 , 625

Received 15th April 2020,

Accepted 12th May 2020

DOI: 10.1039/d0md00122h

rsc.li/medchem

\title{
Defeating the trypanosomatid trio: proteomics of the protozoan parasites causing neglected tropical diseases
}

\begin{abstract}
Anutthaman Parthasarathy (iD) and Karunakaran Kalesh (iD*b
Mass spectrometry-based proteomics enables accurate measurement of the modulations of proteins on a large scale upon perturbation and facilitates the understanding of the functional roles of proteins in biological systems. It is a particularly relevant methodology for studying Leishmania spp., Trypanosoma cruzi and Trypanosoma brucei, as the gene expression in these parasites is primarily regulated by posttranscriptional mechanisms. Large-scale proteomics studies have revealed a plethora of information regarding modulated proteins and their molecular interactions during various life processes of the protozoans, including stress adaptation, life cycle changes and interactions with the host. Important molecular processes within the parasite that regulate the activity and subcellular localisation of its proteins, including several co- and post-translational modifications, are also accurately captured by modern proteomics mass spectrometry techniques. Finally, in combination with synthetic chemistry, proteomic techniques facilitate unbiased profiling of targets and off-targets of pharmacologically active compounds in the parasites. This provides important data sets for their mechanism of action studies, thereby aiding drug development programmes
\end{abstract}

\section{Introduction}

${ }^{a}$ Rochester Institute of Technology, Thomas H. Gosnell School of Life Sciences, 85 Lomb Memorial Dr, Rochester, NY 14623, USA

${ }^{b}$ Department of Chemistry, Durham University, Lower Mount Joy, South Road, Durham DH1 3LE, UK. E-mail: kalesh.karunakaran@durham.ac.uk

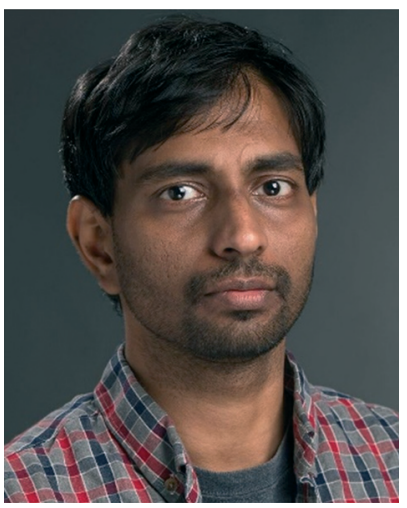

Anutthaman Parthasarathy
Anuthaman Parthasarathy studied Chemistry in India (IITMadras) and obtained his $P h D$ from the International Max Planck Research School (IMPRS) for Microbiology in Marburg, Germany. He was a postdoctoral fellow at the MPI Marburg and at the Stanford University. After leaving Stanford, he set up and run a non-profit science centre for students in his native India. $\mathrm{He}$ is currently a Research Associate at the Rochester Institute of Technology in Rochester, New York, and his current interests include drug discovery, enzymology, microbial metabolism, and the interface of microbiology with chemistry and engineering.
The protozoan parasites Leishmania, Trypanosoma cruzi and Trypanosoma brucei, collectively known as the Tritryps, are the etiological agents of the neglected tropical diseases (NTDs) leishmaniasis, Chagas disease and human African

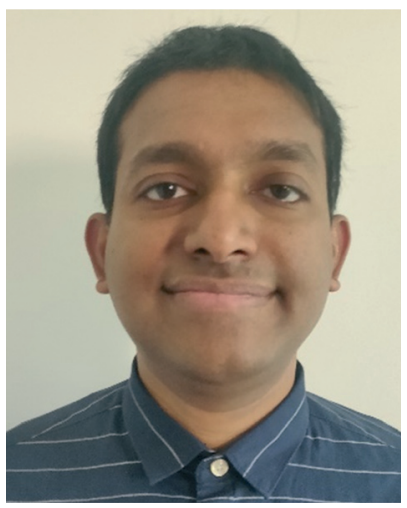

Karunakaran Kalesh
Karunakaran Kalesh has an MSc in Chemistry (IIT Madras) and PhD in Chemical Biology (NUS). Following $P h D$, he was a senior research scientist at AMRI Singapore (2010-2012) and then a Marie Curie Fellow (20122014) at Imperial College London. He was an MRC postdoctoral fellow (2014-2015) and a GSK-Imperial College London Engineered Medicines Laboratory joint postdoctoral fellow (2015-2018) before beginning his independent career at Durham University UK in 2019 as an Assistant Professor (Research). His research focusses on developing and applying chemical biology and mass spectrometrybased proteomics methods for identifying and validating new drug targets for leishmaniasis and Chagas disease. 
trypanosomiasis, respectively. ${ }^{1}$ Collectively, these three diseases account for the highest rates of mortality amongst all NTDs. ${ }^{2}$ The World Health Organisation (WHO) lists these NTDs in a group of high priority diseases that require "innovative and intensified disease management (IDM)" on the basis of several factors including poorly understood disease burden, high management cost, lack of appropriate control methods and relatively low investment in research and development. ${ }^{2}$ Nevertheless, a $90 \%$ reduction in the number of African trypanosomiasis cases has been noticed between 2009 and 2018 thanks to the coordinated efforts by control programmes in endemic countries. ${ }^{3}$ However, a jump of over $26 \%$ in leishmaniasis prevalence has been noticed between 2006 and 2016. ${ }^{4}$ NTDs caused by protozoans continue to be a growing challenge since there is a shortfall in funding and development in this field. ${ }^{5,6}$ Current treatment options, specifically in the case of leishmaniasis and Chagas disease, are severely limited. For instance, in Chagas disease, the only two available drugs, nifurtimox and benznidazole, suffer from toxicity and limited efficacy. $^{7,8}$ Similarly, in the case of visceral leishmaniasis, current front-line medications suffer from issues including high cost, teratogenicity, drug resistance, requirement of non-oral administration and prolonged treatment regimens, making treatment in economically poor endemic areas particularly difficult. ${ }^{9-11}$ There is an urgent need to develop new drugs that can address these shortcomings of the existing ones. An important step towards this goal is the identification and validation of parasite proteins that can act as novel drug targets. This is facilitated by modern proteomics studies that provide a better understanding of the parasite proteome and its functions.

Despite the aforementioned difficulties, many recent developments in the "omics" technologies are gradually transforming the research landscape of NTDs caused by protozoan parasites. The Human Genome Project not only created opportunities to treat genetic diseases, but also triggered the development of a number of sequencing technologies such as ChIP-Seq and RNA-Seq, which are able to provide detailed analyses of cell function. ${ }^{12}$ In general, genomics and transcriptomic techniques allowed the accumulation of large data sets and facilitated increased understanding of the genetic aspects of diseases. ${ }^{13,14}$ Despite all this promise, they have important shortcomings in the investigation of disease states. Not all genes present in a eukaryotic cell are expressed, since protein synthesis is extensively regulated. ${ }^{15}$ mRNA levels are only an estimate of the protein abundance and do not necessarily correlate with protein expression. ${ }^{16}$ This is particularly relevant in the case of Tritryps. ${ }^{17}$ These kinetoplastids are among the most evolutionarily ancient eukaryotic lineages. ${ }^{18,19}$ However unlike higher eukaryotes, gene expression in these parasites is almost exclusively controlled by posttranscriptional mechanisms, making DNA or mRNA-based analyses unreliable for protein identification..$^{20-22}$ An additional handicap is that genomic or transcriptomic profiling cannot identify posttranslational modifications (PTMs), which are often functionally critical. ${ }^{23}$ Understanding protein-protein interactions and protein localisation is essential for obtaining a more complete picture of cell function, but these issues cannot be addressed satisfactorily by DNA or mRNA-based methods in the Tritryps. Finally, DNA-based approaches cannot effectively answer questions on gene function in systems where biological information is lacking. For example, annotations of up to a half of the open reading frames (ORFs) in Leishmania spp. correspond to "hypothetical proteins". ${ }^{24}$ Proteins are the workhorses of the cell, which manifest the end stage of regulation and drive both cellular structure and function, and are thus critical for the understanding of complex processes such as the development of diseases.

Proteomics, which is the systematic analysis of proteins, can provide a more complete picture of global functional protein expression in a cell, tissue or bodily fluid, giving a plethora of information not accessible via other methods. ${ }^{25-27}$ While early proteomics methods were developed for the characterisation of a small number of proteins, later analytical advances allowed the massive parallel detection and comparative studies of thousands of proteins in a single mass spectrometry (MS) run. ${ }^{28}$ Unlike earlier times, proteomics MS is now a genuine hypothesis generation tool in conjunction with cellular, molecular and pharmacological methods. ${ }^{29}$ Today, the investigation of protein complexes and the characterisation of protein pathways via MS methods have become commonplace. More recently, RNA interference (RNAi) has emerged as a common method to disrupt the synthesis of any protein in vivo, offering the means to test the functions of proteins identified by proteomics screens involving hundreds or thousands of candidate proteins. ${ }^{30}$ However, in the field of trypanosomatid parasitology, RNAi has only been used as a genetic tool in T. brucei. Recent proteomic methods have also enabled pathway analysis and have contributed greatly to closing the gaps in knowledge generated by gene-based methods. $^{31}$ Consequently, they have facilitated the identification of biomarkers, to support both diagnostics and evidence-based drug design for disease models. ${ }^{32,33}$ The use of proteomics, however, has its own limitations, especially with respect to the reproducibility of label-free quantifications, necessitating a sufficient number (often more than four) of replications per experimental condition. Additionally, the inherent bias of the MS technique towards abundant proteins sometimes compromises sensitive detection and relative quantification of low-abundant proteins.

This review is not meant to be an exhaustive survey of the proteomics studies of the three protozoan parasites causing NTDs. Instead, this review will highlight the key role that proteomics has played as a particularly relevant technology for shedding light on several aspects of the life process such as life cycle differentiation, stress-adaptation, infectivity and drug resistance of the Tritryps. An overview is provided in Fig. 1. It will also cover important chemical proteomics approaches applied to the three protozoan parasites for the target profiling of pharmacologically active compounds and/or their mechanism of action studies as well as the global profiling and validation of therapeutically relevant PTMs in them. 


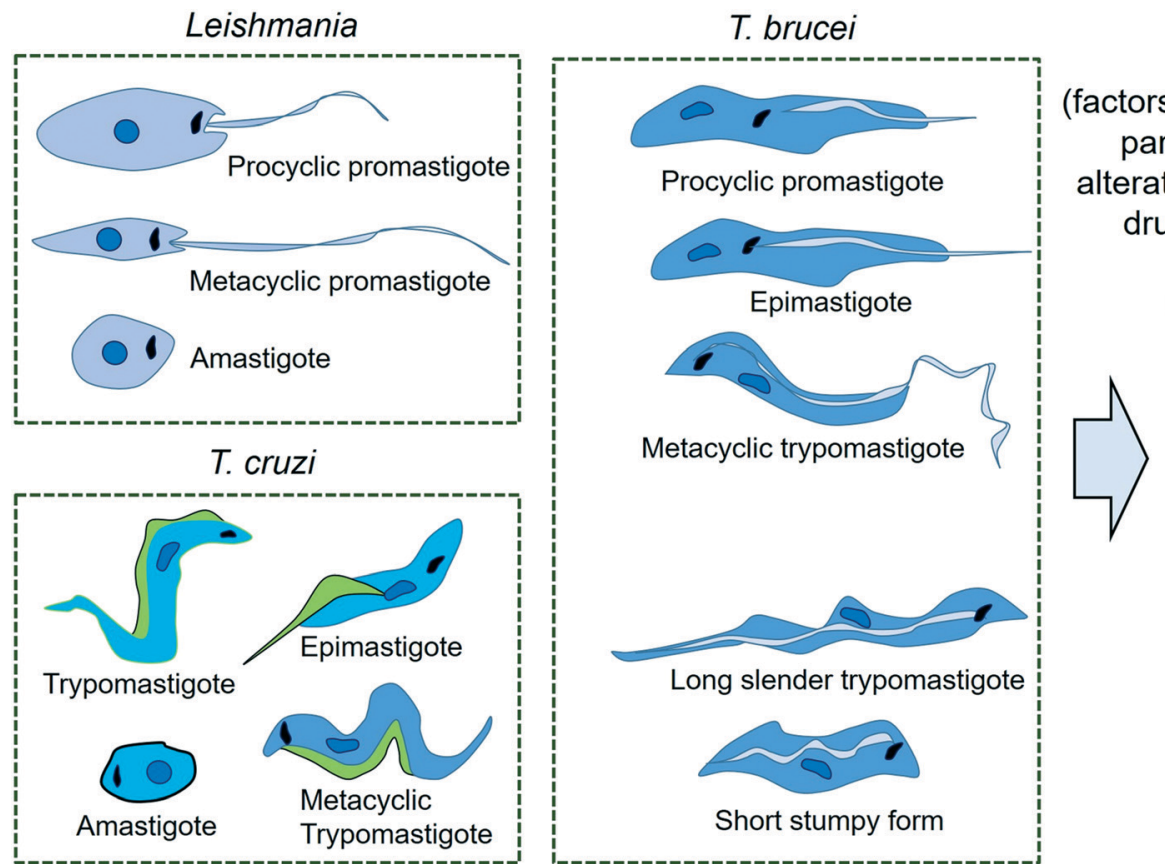

Capture modulation of hundreds to thousands of parasite proteins
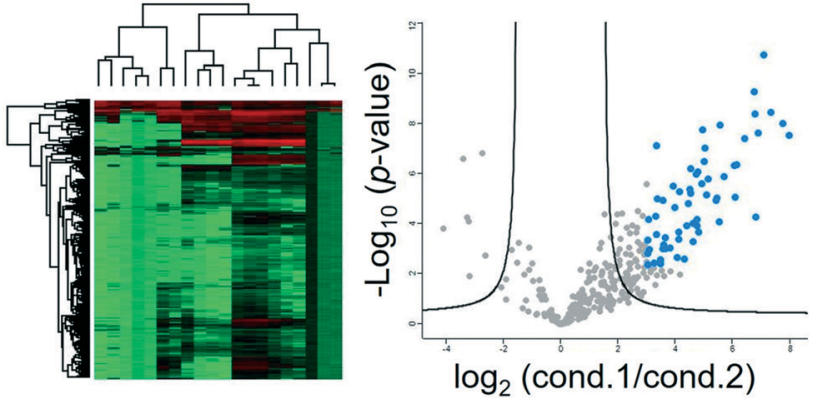

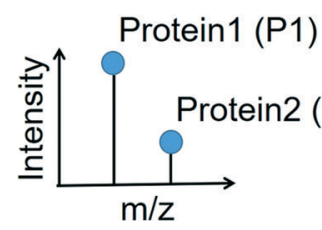

Condition 1
Perturbation

actors that trigger differentiation, parasite-host interactions, alteration in virulence/infectivity, drugs/growth modulators, drug resistance, metabolic labelling,

etc. cell lysis, digestion,

\& sample preparation

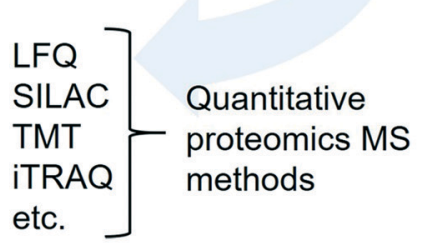

LC-MS/MS
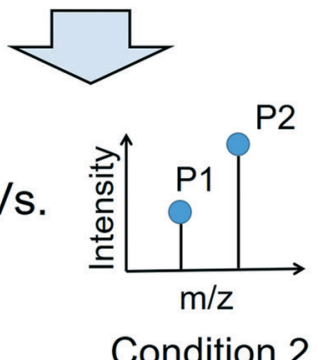

Fig. 1 Overview of proteomics approaches in Tritryps. The proteome of each life cycle stage of a protozoan parasite of interest (Leishmania spp., Trypanosoma cruzi and Trypanosoma brucei) undergoes characteristic modulations as the parasite responds to a perturbation trigger. The perturbation trigger can either be a natural factor that regulates the development of the parasite (such as changes in $\mathrm{pH}$ or temperature, variations in availability of nutrients, and other environmental changes during its transition to a different host species) or a therapeutic intervention such as an inhibitor/growth modulator treatment or a chemical probe treatment. The proteins extracted from a specific life cycle stage of the protozoan parasite of interest following the perturbation window are typically digested to peptides using a protease such as trypsin. The proteomic samples often require additional treatments such as reduction of disulphide bonds, alkylation of free thiols and extensive clean-up or desalting procedures. The relative expression changes in several hundreds to thousands of proteins across different conditions are then measured with the liquid chromatography-tandem mass spectrometry (LC-MS/MS) technique following a suitable quantitative proteomics approach such as label-free quantification or one of the different types of label-based quantification methods. Processing, analyses and visualisation of the large proteomics data sets are carried out using dedicated software programmes.

\section{Proteomics approaches in Leishmania}

\subsection{Leishmaniasis: an introduction}

Leishmaniasis is a complex disease caused by about 20 species of protozoan parasites of the genus Leishmania, ${ }^{34}$ which is transmitted to humans via the bites of blood-sucking sandflies. About 200 million people in over 90 countries in Asia, Africa, Latin America and southern Europe live at the risk of exposure to the parasite, ${ }^{35}$ with about 2 million new cases of leishmaniasis and 20000-50000 deaths annually. ${ }^{34}$ Leishmaniasis affects mainly people experiencing poverty, malnutrition, immune suppression, and pre-existing health issues or people living in deforested areas undergoing rapid urbanisation. ${ }^{34}$ The disease has three forms: cutaneous, mucocutaneous and visceral. While the other two forms are persistent and disfiguring, visceral leishmaniasis causes significant mortality and morbidity. ${ }^{35}$ Current Leishmania therapies are largely inadequate. Only one antileishmanial compound, miltefosine, is available for oral administration. The drug is, however, a known teratogen and therefore unsuitable for use in pregnant women. ${ }^{36}$ Other frontline treatments such as amphotericin B (and its liposomal formulations) and paromomycin require prolonged treatment regimens and are 
unsuitable for administration in resource-limited endemic areas. $^{11,37}$ The old antimonial drugs suffer from widespread resistance and are notorious for their toxicity. ${ }^{38}$ In general, all currently available antileishmanials suffer from moderate to severe toxicity, resistance and/or clinical relapse. ${ }^{10}$ Currently there are no new therapeutics for leishmaniasis in clinical development, and only a few in the preclinical stages. Alarmingly, not only is there a scarcity of validated molecular targets for drug development, but also a lack of knowledge on the mechanisms of action of existing molecules approved for clinical use. There is thus a dire need for new treatments, particularly oral drugs, for visceral leishmaniasis.

\subsection{The Leishmania life cycle}

Leishmania spp. have a digenetic life cycle that alternates between intracellular amastigotes in the vertebrate host and multiple extracellular promastigote stages in the bloodsucking sandfly vector. The growth cycle of the parasite in the sandfly begins with weakly motile but highly proliferative procyclic promastigotes in the midgut and culminates in the non-dividing but strongly motile and infectious metacyclic promastigotes. Once inside the vertebrate host, the metacyclic promastigotes transform into non-motile amastigotes, which replicate predominantly inside the immune cells, especially macrophages. Amastigote proliferation eventually leads to host cell rupture, allowing entry into the host's blood stream and infection of other phagocytes. The amastigotes in the host's bloodstream can be taken up by another sandfly during its blood meal. In this case, the amastigotes transform into procyclic promastigotes in the sandfly's midgut, multiply by binary fission and continue the life cycle.

\subsection{Tracking variations in the parasite proteome for the molecular characterisation of key life processes}

In the early days of proteomics, the technique of choice for proteome resolution was two-dimensional gel electrophoresis (2-DE). This method allows separation of proteins in a cell lysate according to their isoelectric points and molecular masses. The resolved proteins are typically visualised by protein staining, for instance by silver staining or by Coomassie blue dye. The first report of Leishmania proteomics employed 2-DE for revealing distinct protein patterns between different $L$. tropica isolates causing simple cutaneous leishmaniasis and those causing leishmaniasis recidiva, a rare variant of cutaneous leishmaniasis. ${ }^{39}$ Later, in order to gain insights into the molecular basis of the parasite virulence in cutaneous leishmaniasis, protein patterns of radiolabelled clones of infective and non-infective types generated from a single isolate of $L$. tropica were compared. ${ }^{40}$ Although the observed protein patterns of the different clones showed only minor differences, which could partly be attributed to the limited sensitivity of the techniques employed, this study showed the scope of using protein profile differences to classify the infective and non-infective
Leishmania isolates. 2-DE proteome patterns have also been demonstrated to be useful for highlighting the differences between two different species of New World Leishmania ( $L$. mexicana and L. braziliensis) and for establishing relatedness between subspecies. ${ }^{41}$

By the 1980s, the combination of 2-DE with MS gained popularity. Several groups employed this combination for gaining insights into the molecular mechanisms of Leishmania differentiation. Nugent et al. used 2-DE to resolve the proteome of axenically differentiated $L$. mexicana parasites and observed about 2000 protein spots in the different life cycle stages of the parasite. ${ }^{42}$ Several spots were found to be life cycle-specific with the majority of unique spots showing expression in the infective metacyclic and amastigote stages. MS analyses of selected excised gel spots led to the identification of 47 parasite proteins. Intriguing findings include highly upregulated and preferential expression of proteins involved in protein synthesis such as eukaryotic translation elongation factor-1 alpha (eIF-1 $\alpha$ ), eukaryotic initiation factor-5 alpha (eIF-5 $\alpha$ ) and $40 \mathrm{~S}$ ribosomal protein $\mathrm{S} 2$ after differentiation, as well as the exclusive detection of certain heat-shock proteins (HSPs) (e.g. HSP60 and HSP70) in the amastigotes.

As only the metacyclic form of the parasite infects vertebrate hosts, some proteomics studies have focussed on identifying the proteins that are differentially expressed in this stage. Mojtahedi et al. employed the 2-DE-MS combination for comparing the proteomes of $L$. major procyclics and metacyclics. ${ }^{43}$ Consistent with the high motility and arrested growth of the metacyclic parasites, they observed an increased abundance of several proteins that facilitate parasite motility, whilst the abundance of many proteins involved in protein synthesis decreased. In a more recent study, Moreira et al. applied a liquid-based free-flow electrophoresis method for resolving the proteome of $L$. infantum wild-type and a pteridine reductase 1 (PTR1) nullmutant in the metacyclic and procyclic stages. ${ }^{44}$ The PTR1 null-mutant presented reduced levels of intracellular tetrahydrobiopterin, an important growth factor for Leishmania. A reduced level of pterins has been proposed as one of the factors facilitating the metacyclogenesis. MS proteomics revealed significantly altered expression of several structural proteins and metabolic enzymes between the two developmental stages in the contexts of both reduced and normal pterin levels.

Many important molecular processes in the Leishmania life cycle were revealed thanks to the development of axenic promastigote cultures of the parasite. However, long-term maintenance of the parasites in host-free cultures has been shown to affect the infectivity and virulence. ${ }^{45}$ Nevertheless, Leishmania axenic cultures also provide a convenient means to generate drug resistant strains in the laboratory. ${ }^{46}$ Intuitively, the comparative proteomic study of a resistant strain against its non-resistant counterpart could reveal proteins associated with drug resistance. Walker et al. applied this concept for deconvoluting the molecular factors 
associated with resistance to trivalent antimony treatment in L. panamensis strains that were made resistant to the drug in cultures. ${ }^{47}$ They have identified nine differentially expressed proteins, which include stress-responsive proteins and important metabolic enzymes $S$-adenosylmethionine synthetase (SAMS) and $S$-adenosylhomocysteine hydrolase (SAHH). Both SAMS and SAHH play key roles in the pathways upstream of the biosynthesis of trypanothione, a unique thiol metabolite of Kinetoplastida that is implicated in antimony resistance and the parasite's response to oxidative stress. ${ }^{48,49}$

\subsection{Application of quantitative proteomics MS in the study of Leishmania parasites}

Conventional 2-DE is now obsolete, with quantitative proteomics MS techniques offering a far better sensitivity of detection, the capability for high-throughput whole proteome analysis in a single MS run and the quantitative comparison of multiple experimental conditions in a single experiment. Quantitative proteomics MS techniques are broadly divided into label-free quantification (LFQ) methods, such as MS1intensity based methods $\mathrm{s}^{50}$ and spectral counting-based methods, ${ }^{51}$ and several different labelling-based methods. Popular labelling strategies include TMT (tandem mass tag), ${ }^{52}$ iTRAQ (isobaric tagging for relative and absolute quantitation), ${ }^{53}$ SILAC (stable isotope labelling by amino acids in cell culture $)^{54}$ and stable isotope dimethyl labelling. ${ }^{55}$

2.4.1 Study of host-Leishmania interactions. Today, quantitative proteomics MS offers unprecedented capabilities for correlating protein expression profiles with the phenotypes of the parasites. It has now evolved as a robust technology for identifying and differentially quantifying virulence markers of different Leishmania species and strains, enabling in-depth investigation of host-Leishmania interactions. Rezende et al. used LFQ MS proteomics to accurately capture the differential abundance of several virulence factors of two different strains of the $L$. amazonensis species, namely PH8 and LV79. ${ }^{56}$ They compared the lesion development by the two strains in mice and observed that the PH8 strain is the more virulent type. Additionally, lesionderived amastigotes from the $\mathrm{PH} 8$ strain were reported to be more viable and more infective in vitro. LFQ comparison of the lesion-derived soluble amastigote proteome of the two strains revealed strikingly different protein abundance patterns between them. The virulence factor GP63 metalloprotease was more abundant in the PH8 strain, whilst virulence factors such as HSP70, tryparedoxin peroxidase, superoxide dismutase and elongation factor 2, were relatively more abundant in the LV79 strain. Menezes et al. applied multidimensional liquid chromatography-tandem MS to study the effects of Leishmania infection on a CBA murine macrophage cell line resistant to $L$. major but susceptible to $L$. amazonensis. ${ }^{57}$ They showed that the two different parasite species differentially modulate several host-cell metabolic proteins during the initial stages of Leishmania-macrophage interaction. The differentially modulated metabolic proteins identified are potentially the key drivers for the distinct phenotypic macrophage responses observed (infection control during L. major vs. parasite survival during L. amazonensis infection). An iTRAQ quantitative proteomics study by Singh et al. that compared the protein expression profiles of an $L$. donovani infected THP-1 cell line also revealed the modulation of several important host-cell metabolic pathways including glycolysis and fatty acid oxidation. ${ }^{58}$ Another important proteomic study shed light on the virulence mechanism of the GP63 metalloprotease in Leishmania. ${ }^{59}$ Comparative proteomics of an immortalised murine bone marrow derived $\mathrm{M} \varphi \mathrm{LM} 1$ cell line following infection with $L$. major WT and L. major GP63-/- revealed extensive alterations within the nuclear proteome of the host cell. ${ }^{59}$ Importantly, the host cell nuclear protein pattern following infection with L. major GP63-/- resembled that of non-infected cells, indicating that the virulence mechanism of the GP63 protease operates by modulating the host cell nuclear proteome.

Proteomics analyses of biological membranes is an underrepresented area even though membrane proteins constitute about $30 \%$ of a typical proteome. ${ }^{60}$ This is because many membrane proteins tend to aggregate and precipitate in the solution, making sample preparation notoriously difficult. However, several membrane proteins have been implicated in crucial roles in Leishmania-host interactions. ${ }^{61}$ Lynn et al. isolated the membrane proteins of promastigote and amastigote stages of $L$. mexicana and L. infantum parasites using Percoll density gradients and profiled the differentially expressed proteins using iTRAQ quantitative proteomics MS. ${ }^{62}$ They identified 107 L. mexicana and 189 L. infantum nonredundant proteins, of which $20-40 \%$ showed significantly different abundance levels between the two life cycle stages.

2.4.2 Profiling of the mRNA-bound Leishmania proteome. As the gene expression in Leishmania is predominantly controlled at the posttranscriptional level by mRNA degradation and translation, efforts have been devoted to profiling the mRNA-binding proteins (RBPs) of the parasite. Towards this goal, Nandan et al. developed a workflow that involves UV light-mediated covalent cross-linking of RBP to mRNA in the live parasites followed by cell lysis and capturing of the interactome using oligo(dT) magnetic beads. ${ }^{63}$ The bound protein-mRNA complexes can be eluted following RNase treatment and analysed by tandem MS. Using this methodology, they identified 79 mRNA-binding proteins in $L$. donovani axenic amastigotes. The majority of the identified mRNA binders in this study had no homologues or orthologues in humans, pointing to the possibility that the data set may represent an important resource for choosing selective drug targets in future drug development programmes. de Pablos et al. recently adapted this approach, combining it with LFQ proteomics MS for profiling the mRNA-binding proteome of the different life cycle stages of $L$. mexicana parasites. ${ }^{64}$ They observed a low correlation of the protein expression with the transcript, and parasite life cycle-dependent modulation of the mRNAbinding proteome enrichment. 
2.4.3 Chemical proteomics in Leishmania. Chemical proteomics is a rapidly growing interdisciplinary science that uses synthetic chemical probes to understand protein function. ${ }^{65,66}$ It enables the elucidation of the binding engagements of pharmacologically active compounds with their target protein(s) and facilitates their mode of action studies. It also provides an alternative method to enrich and characterise certain protein modifications, including PTMs, for which conventional enrichment strategies often fail or tend to be less effective. Another important capability of chemical proteomics is the robust and unbiased global profiling of substrates of PTM-generating enzymes and shedding light on the modulatory effects of active/lead compounds or drugs on these substrates in a highthroughput manner. In the following section, we will discuss some important findings on the Leishmania proteome revealed by chemical proteomics methods.

2.4.3.1 Target fishing and mode of action studies. Deconvoluting the mode of action of a pharmacologically active chemical entity is a daunting task in drug discovery programmes. A combination of complementary methods is often required to identify the real target(s) and mode of action. Wyllie et al. recently employed quantitative chemical proteomics MS and in vitro evolution combined with wholegenome analysis ${ }^{67}$ to identify cyclin dependent kinase 12 (CDK12) (also known as cdc-2-related kinase 12 or CRK12) as the principal molecular target of their preclinical pyrazolopyrimidine compound DDD853651 or GSK3186899 (compound 1 in Fig. 2) for visceral leishmaniasis. ${ }^{68}$ They first developed a series of analogues (compounds 4-7, Fig. 2) of DDD853651 with a polyethylene glycol (PEG) linker, which after attaching to magnetic beads were used for competitive chemical proteomic pulldown experiments. With compound 4 immobilised on beads, SILAC "light" and "heavy" labelled L. donovani promastigote lysates were used for fishing out the protein binders in the presence and absence respectively of the structurally related competitive inhibitor compound $\mathbf{5}$. This quantitative proteomics MS experiment identified CDK12 along with several other cyclin-dependent kinases and a few other proteins as selective binders of compound 4. A second round of competitive chemical proteomics experiments using the more potent inhibitors 2 and 3 as

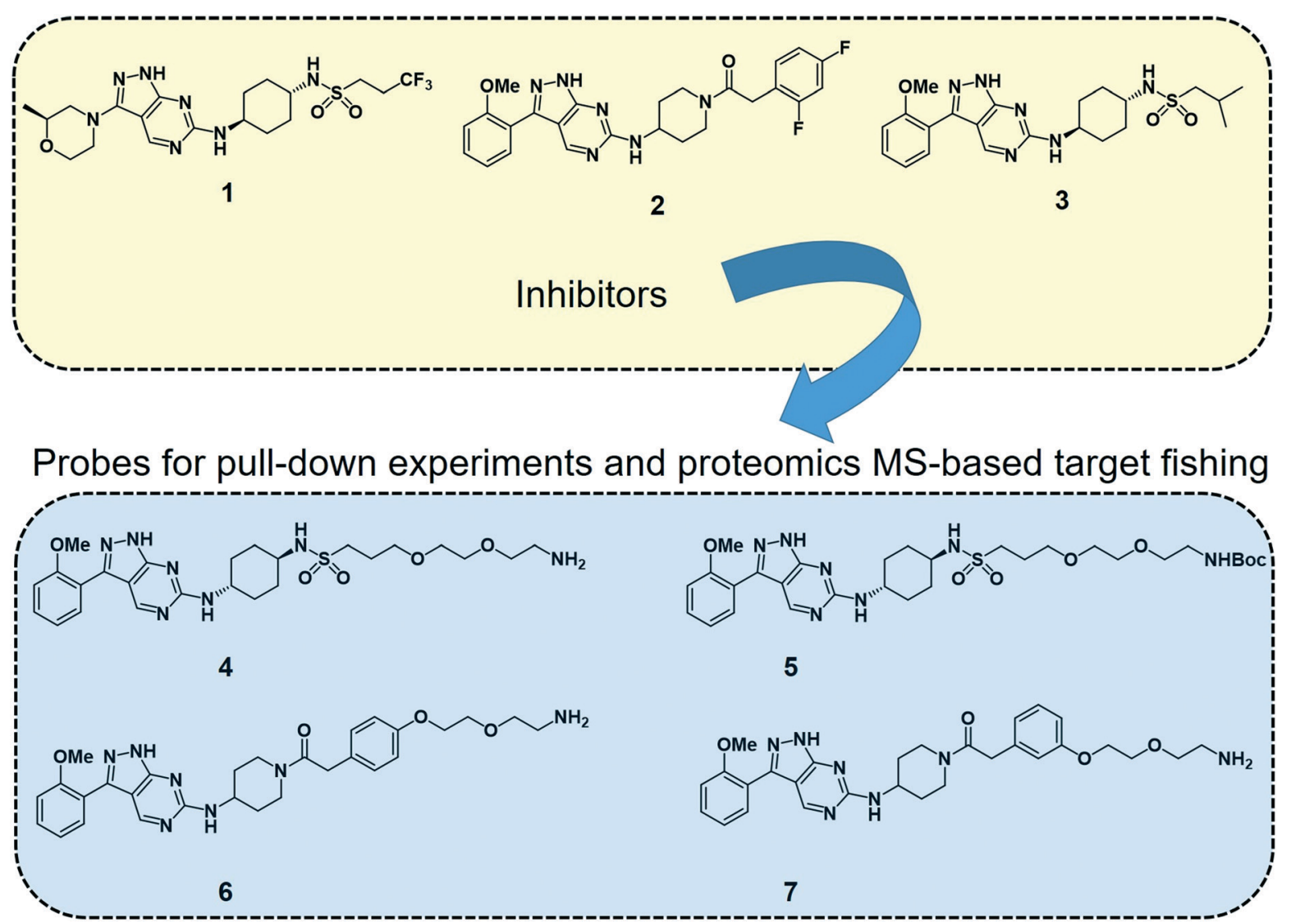

Fig. 2 Leishmania CDK12 inhibitors and chemical probes from a pyrazolopyrimidine series used in the proteomics MS-based target profiling and mode of action studies. ${ }^{68}$ Compound 1 (known as DDD853651 or GSK3186899) is a preclinical developmental compound against visceral leishmaniasis. 2 is another potent compound with an aminopiperidine amide functionality. Compound 3 carries an isobutyl group and 2-methoxyphenyl group in place of the trifluoropropyl and 2-methylmorpholine groups in compound 1. Compounds 4 to 7 are structurally related pyrazolopyrimidines with polyethylene glycol linkers. The primary amino groups in 4, 6 and 7 were used for immobilising the compounds on magnetic beads, facilitating affinity enrichment of the protein binders of the compounds from SILAC-labelled parasite cell lysates, whereas compounds 5, 2 and 3 were used as in-solution competitive binders of the proteins in the affinity-enrichment experiments. 
competitive binders, and beads derivatised with compounds 4, 6 and 7 also revealed a more or less similar set of selective binders. They subsequently generated drug resistant strains of the parasites and performed whole-genome sequencing, which identified a key mutation in the catalytic site of the CDK12 protein. Additionally, CDK12 overexpressing parasite strains showed increased sensitivity to the compound, indicating that CDK12 is indeed the principal target of the pyrazolopyrimidine compound. In this case, the chemical proteomics alone was not sufficient to identify the major target of the compound. Nevertheless, it helped to narrow down the likely candidates to a small set of proteins to permit subsequent genetic target validation studies.

Thermal proteome profiling (TPP) and the related cellular thermal shift assay (CETSA) are complementary to the chemical probe-based target deconvolution methods. ${ }^{69-71}$ These are based on the principle that binding of a ligand to a protein target often increases the melting temperature $\left(T_{\mathrm{m}}\right)$ of that protein. Therefore, when a drug-treated whole-proteome is heated, unbound proteins may denature and precipitate while the ligand-bound protein(s) remain in solution. Typically, samples are treated to different temperatures and the soluble portion of the proteome from each temperature treatment is analysed by LC-MS/MS. It is often used in combination with a quantitative proteomics MS method such as TMT labelling, which permits the defining of the aliquot from each temperature treatment using a specific isobaric label. The target engagement of an $\mathrm{N}$-myristoyltransferase (NMT) inhibitor compound termed DDD1000097 in the L. donovani promastigote proteome was recently unravelled using the TPP method. ${ }^{72}$ Corpas-Lopez et al. treated $L$. donovani promastigote lysates with DDD1000097 and the soluble proteome from the aliquots heated to different temperatures was treated with TMT-10plex labels. ${ }^{72}$ DMSO treatment instead of the inhibitor treatment was used as a control. The data revealed the $L$. donovani NMT protein as the most significant hit, with a $3.3^{\circ} \mathrm{C}$ increase in melting temperature $\left(\Delta T_{\mathrm{m}}\right)$ of the protein following the inhibitor binding. Although currently limited to soluble proteins, TPP and CETSA are useful proteomics methods for the target deconvolution of non-covalent binders.

2.4.3.2 Global profiling of substrates of $N$-myristoyltransferase in Leishmania. The enzyme NMT that catalyses N-terminal myristoylation of glycine residues in proteins is one of the few solidly validated druggable targets in Leishmania. ${ }^{73}$ By using a terminal alkyne analogue of myristic acid, Wright et al. metabolically labelled the

(A)

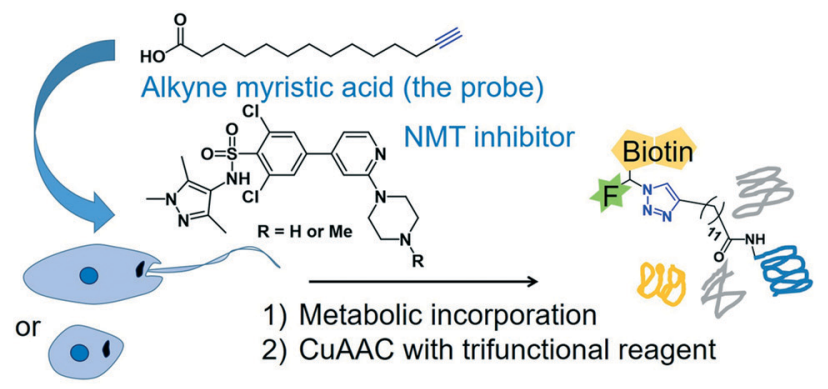

1) Affinity enrichment

2) On-bead digestion

3) $\mathrm{LC}-\mathrm{MS} / \mathrm{MS}$
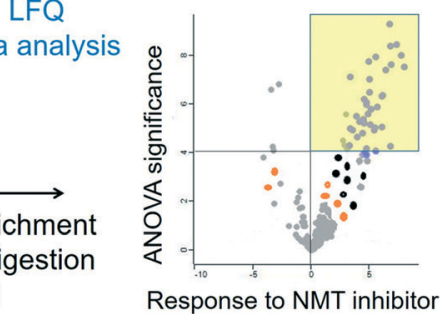

(B)
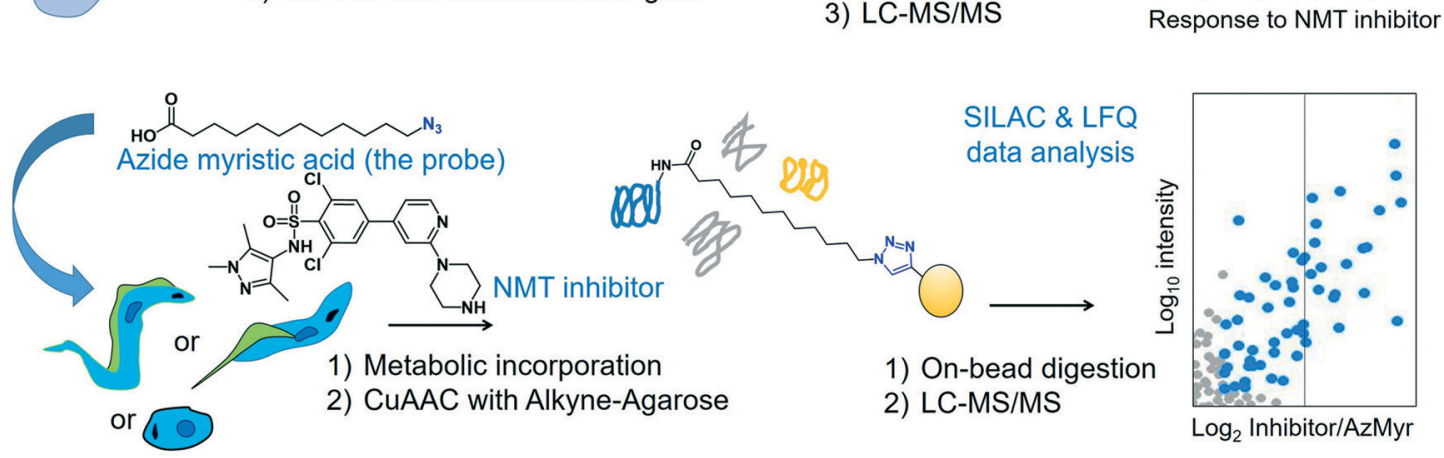

(C)
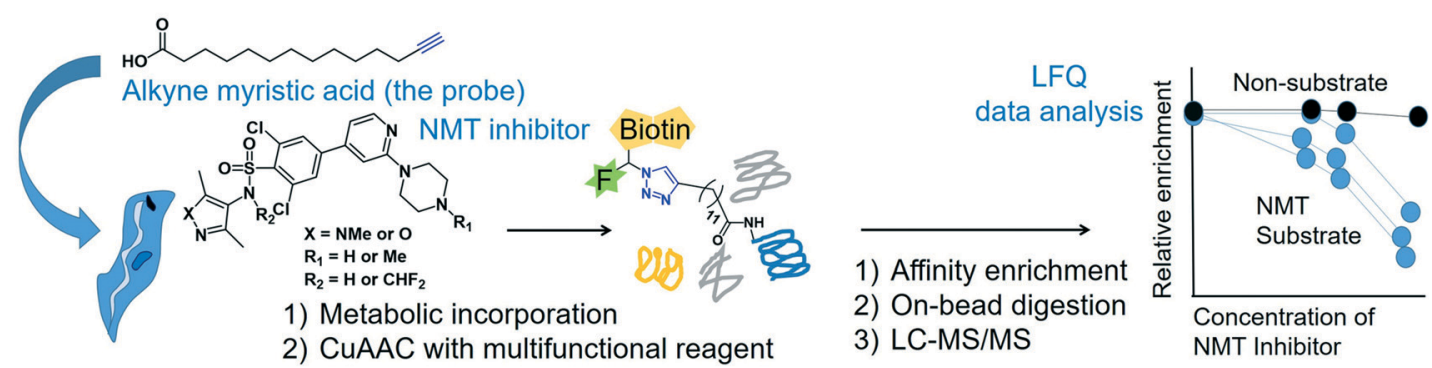

Fig. 3 Proteomics MS profiling of substrates of $\mathrm{N}$-myristoyltransferase in (A) Leishmania donovani (promastigotes and amastigotes), ${ }^{74}$ (B) Trypanosoma cruzi (epimastigotes, trypomastigotes and amastigotes) ${ }^{141}$ and (C) Trypanosoma brucei (bloodstream form). ${ }^{193}$ 
$N$-myristoylome of $L$. donovani promastigotes and axenic amastigotes. $^{74}$ Affinity enrichment of the alkyne-modified parasite proteins using a multifunctional capture reagent exploiting the copper(I)-catalysed azide-alkyne cycloaddition (CuAAC) click reaction ${ }^{75}$ enabled LFQ proteomics MS profiling of the parasite $N$-myristoylome (Fig. 3A). They identified 113 and 49 myristoylated proteins in the promastigotes and amastigotes, respectively. Intriguingly, the majority of the identified proteins did not contain the essential $\mathrm{N}$-terminal glycine residue for $\mathrm{N}$-myristoylation, indicating that some of the observed modifications may have a non-enzymatic origin and (or) that enzymes other than NMT may have contributed to the observed labelling. Therefore, in order to identify the specific NMT substrates in the parasites, the researchers applied the metabolic labelling approach in combination with a chemical knockdown of the NMT protein using inhibitors. Although pre-incubation of the parasites with the NMT inhibitors led to a reduction in the fluorescent labelling, the LFQ proteomics experiments in amastigotes did not reveal a uniform reduction of myristoylation upon inhibitor treatment. However, a subset of the enriched proteome (30 proteins in this study) quantitatively responded to the NMT inhibitors. These proteins all contain the $\mathrm{N}$-terminal glycine residue, indicating that they are substrates of the NMT enzyme in the parasite. This highlights the power of chemical proteomics for characterising the true substrates of an enzyme of potential therapeutic relevance in the parasite.

2.4.3.3 Quantitative profiling of de novo protein synthesis in Leishmania during starvation. Many studies point to the adaptation of Leishmania parasites to nutrient scarcity as playing potentially important roles in the differentiation process. $^{76-78}$ A method that could accurately and quantitatively profile protein synthesis in the parasite during a period of severe nutrient scarcity holds great potential for elucidating the molecular processes facilitating adaptation to such conditions. Towards this goal, we have recently developed a methodology that combined the BONCAT (bioorthogonal non-canonical amino acid tagging) technology ${ }^{79}$ with iTRAQ quantitative proteomics $M S$ in starving $L$. mexicana promastigotes. ${ }^{80}$ In this approach, the methionine surrogate, azidohomoalanine (AHA), was metabolically incorporated into newly synthesised proteins (NSPs) of the parasites subjected to nutrient deprivation for different durations. Following cell lysis, the whole cell proteome from each starvation window was separately subjected to click chemistry using a biotin-azide capture reagent, which enabled the selective tagging of the NSPs with biotin. The biotinylated NSPs were affinity-enriched on streptavidin beads, and after stringent washings, the bound proteins were subjected to on-bead tryptic digestion. The tryptic peptides from different starvation windows were labelled with different iTRAQ labels and following the completion of the labelling reactions, the samples were pooled together and analysed by LC-MS/MS (Fig. 4). The multiplexed iTRAQ approach enabled temporally resolved quantitative profiling of over 250 starvation-specific NSPs in the parasite. This study revealed a starvation-specific increase in the abundance of several translation-regulating and stress-responsive proteins, pointing to their important roles in the starvationadaptation of the parasite. Besides, this study provides a robust methodology for analysing protein synthesis in the parasite in a quantitative and temporally resolved manner.

\section{Proteomics approaches in Trypanosoma cruzi}

\subsection{Chagas disease: an introduction}

Chagas disease (American trypanosomiasis) is caused by Trypanosoma cruzi (T. cruzi) and is endemic in Latin America,
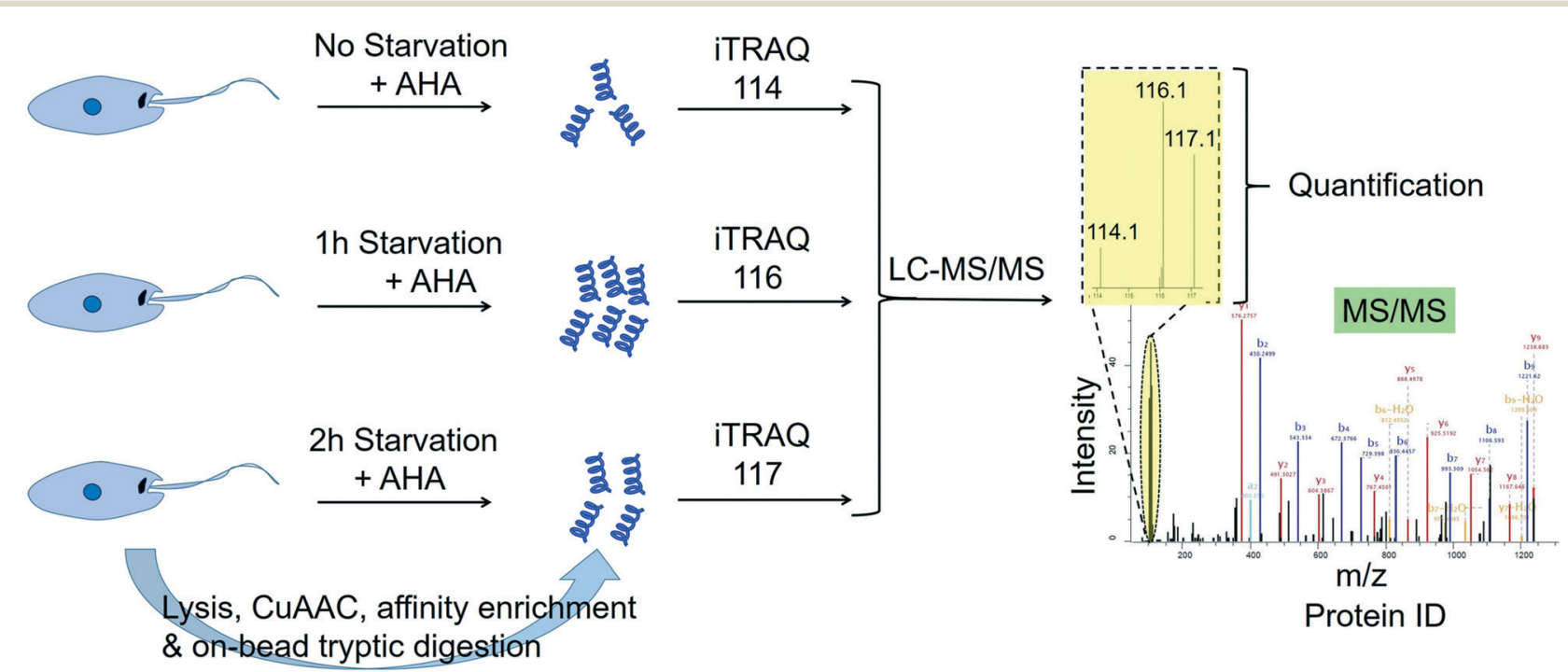

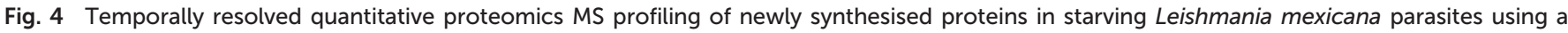
BONCAT-click chemistry affinity enrichment-iTRAQ combination. ${ }^{80}$ 
with a wide distribution of cases from the southern US to northern Argentina. ${ }^{81}$ It is transmitted to humans via bloodsucking triatomine bugs (or "kissing bugs") and also spreads by migration and blood transfusion. ${ }^{81}$ Early symptoms may include fever, headaches, swelling at the bite site and lymph node swelling. About one-quarter to a third of patients may develop chronic infections. Some patients develop enlargement of the heart ventricles, oesophagus or colon and digestive or neurological complications up to 30 years after the initial infection. ${ }^{82}$ Chemotherapy to treat Chagas disease is reliant mainly on benznidazole (Bzn) and nifurtimox ( $\mathrm{Nx}$ ), which were discovered over 40 years ago. They are efficient in treating the acute phase, but of limited use in countering the chronic phase. Both drugs have substantial side effects, need long-term administration and are ineffective against diverse strains, with certain strains being resistant to Bzn. ${ }^{83,84}$ Thus, improved drugs, especially for the chronic stages, are an urgent need. To make matters worse, only a few compounds are in the clinical assay stage, although diverse natural and synthetic compounds have in vivo and in vitro activity.

\subsection{The $T$. cruzi life cycle}

In the bloodstream of infected vertebrate hosts, $T$. cruzi exists in a non-replicative trypomastigote form. When a triatomine vector takes a blood meal from the infected host, the T. cruzi in the blood meal transforms into the epimastigote form inside the bug's midgut. The parasite then travels to the bug's hindgut where it differentiates into infective metacyclic trypomastigotes. When the infected bug takes a blood meal again, it releases these infective trypomastigotes in its faeces near the bite site. Once the trypomastigotes enter the vertebrate host's cell, they differentiate into intracellular amastigotes, which replicate by binary fission. The amastigotes further differentiate into trypomastigotes and enter the bloodstream. T. cruzi is considered a heterogeneous species with a variety of strains in different vectors and mammalian hosts, leading to a high variability in virulence. ${ }^{85}$

\subsection{Characterising the life cycle stages of $T$. cruzi}

The proteome mapping of T. cruzi has enabled the description of stage-specific protein expression and led to the discovery of some proteins responsible for drug resistance. ${ }^{86-88}$ In the trypomastigote stage, the parasite relies more on glycolysis than the mitochondrial electron transport chain to meet the energy demand. ${ }^{89}$ Epimastigotes of the CL Brener reference strain not only had elevated levels of tubulin and heat shock proteins, which were present in multiple isoforms, but also expressed arginine kinase, an enzyme not found in mammals, thus presenting a potentially novel therapeutic target. ${ }^{90}$ Differential proteomic analysis led to the identification of 22 proteins, mostly metabolic proteins of the glycolytic pathway (enolase, pyruvate kinase and 2,3-bisphosphoglycerate mutase), along with cytoskeletal structural proteins, polypeptide synthesis and chaperones/heat shock proteins. ${ }^{91}$ Antioxidant defence enzymes were implicated in drug detoxification after prostaglandin F2 $\alpha$ synthase was identified as one of the proteins. ${ }^{92}$ The shotgun proteome of the blood trypomastigote (BT) stage showed that the major groups were trans-sialidase (TS), bioenergetics-related enzymes, chaperones, and cytoskeletal proteins. ${ }^{93}$ Comparison of the BT proteome with that of the tissue culture-derived trypomastigote (TCDT) or metacyclic trypomastigote (MT) demonstrated that over 2200 proteins were unique to the BT stage and were involved in a variety of cellular processes. ${ }^{93}$

A large-scale comparative proteomic study showed that the metacyclic form had the highest number of proteins expressed, followed by amastigotes, epimastigotes and trypomastigotes. ${ }^{86}$ The same study also reported that over a third of the total proteome, accounting for over 1000 proteins, consisted of those annotated as "hypothetical". One notable observation was that the four stages of the parasite might be characterised by distinct energy metabolites, such as histidine during the insect stages and fatty acids during the intracellular amastigotes in the mammal. Another study based on only basic proteins found that epimastigotes may use amino acid metabolism, but TS enzymes and flagellar rod components were specific for trypomastigotes. ${ }^{94}$ Amastigotes also appeared to be rich in vesicular trafficking proteins, and several important antioxidant enzymes such as ascorbate peroxidase, mitochondrial tryparedoxin peroxidase, trypanothione synthase and iron superoxide dismutase were abundant in the metacyclic form, suggestive of parasite anticipation of an oxidative attack by host phagocytes. ${ }^{86}$ Proteomic analysis of the trypomastigote stage identified over 1400 proteins, nearly $14 \%$ of which were mainly glycophosphatidylinositol (GPI)-anchored surface proteins that may be involved in host cell invasion and immune evasion. ${ }^{95}$ Epimastigotes and trypomastigotes differed in over $50 \%$ of the expressed proteins according to one study, which also identified some candidates with different isoforms involved in metacyclogenesis. ${ }^{96}$

During metacyclogenesis, the proteome undergoes major changes due to nutritional stress and at different time-points after adhesion. A large-scale proteomic investigation led to the observation of major differences in proteins involved in oxidative stress, protein translation, and metabolic pathways pertaining to proteins, lipids, and carbohydrates. $^{97}$ Quantitative phosphoproteomic analysis in the same report showed over 7000 phosphorylation sites, of which 260 were regulated differentially, including some potential drug targets such as the enzymes of sterol biosynthesis. A later study reported that during nutritional stress, proteins with various functions, such as fatty acid synthesis and regulation of protein expression, were phosphorylated, which could in turn trigger metacyclogenesis. ${ }^{98}$ The T. cruzi epimastigote enters the stationary phase from the exponential phase, leading to the early stages of metacyclogenesis. A proteomic comparison of the exponential and stationary phases of epimastigotes was able to quantify over 3000 proteins; ribosomal proteins were upregulated in the exponential phase, whereas proteins involved in autophagy were upregulated in the stationary 
phase. ${ }^{99}$ Further, the same report demonstrated the regulation of proteins via $\mathrm{N}$-terminal acetylation during this transition from the exponential to the stationary phase.

The transition from trypomastigotes to amastigotes, known as amastigogenesis, has also been investigated by quantitative proteomics and phosphoproteomics approaches. A number of proteins were regulated in this context, and the majority of regulated proteins were membrane proteins. ${ }^{100}$ The differentiation of infective trypomastigotes to epimastigotes is termed epimastigogenesis and is among the least studied processes in the trypanosome field. An in vitro method to generate epimastigotes revealed a previously uncharacterised stage called the "recently differentiated epimastigotes", which resisted complement-mediated lysis in vivo and in vitro. ${ }^{101}$ Later, proteomic studies identified certain proteins, which were upregulated solely in the recently differentiated epimastigotes, such as $\mathrm{ABC}$ transporters and the multidrug resistance protein E. ${ }^{102}$

\subsection{Study of host-T. cruzi interactions}

The cell surface of $T$. cruzi features a dense layer of GPIanchored molecules, which mediate a variety of interactions of the parasite with its insect vector and mammalian hosts. A comparison of the cell surface proteomes during different stages revealed that the majority of proteins are expressed in more than one stage, but a few are stage specific. ${ }^{100}$ Further analysis indicated that most of the proteins were membranederived and could participate in invasion, adhesion, cell signalling and modifying the host's immune response. The proteomic analysis of membrane-associated fractions from epimastigotes and MT stages showed that over 200 proteins had predicted sites for post-translational lipid modifications, signal sequences or transmembrane domains. ${ }^{103}$ Interestingly, the MT stage expressed a large set of surface glycoproteins involved in host cell adhesion and invasion, while epimastigotes did not.

T. cruzi is an intracellular pathogen and hence, adhesion and invasion of the host cell are crucial processes. Interaction with host cells involves both surface and secreted molecules. Secreted molecules are known to play critical roles in immune evasion, migration inside the host tissues, cell adhesion, communication, differentiation, and parasite proliferation. ${ }^{104}$ A novel family of surface membrane proteins called TcSMP (T. cruzi surface membrane proteins) conserved in different $T$. cruzi lineages has been characterised. ${ }^{105}$ Evidence suggests that the TcSMP are membrane-spanning and might be released into the extracellular environment. They were shown to bind mammalian cells, and trigger $\mathrm{Ca}^{2+}$ dependent signalling and lysosome exocytosis, linking them to host cell invasion. The secretome of T. cruzi consists of extracellular vesicles and soluble proteins not associated with vesicles. ${ }^{106}$ Metabolic proteins, as well as proteins implicated in cell signalling, parasite survival, nucleic acid packaging and virulence were detected by LFQ proteomics. ${ }^{106}$ The exoproteome of the TCDT stage was characterised in the $\mathrm{Y}$ strain as having 540 proteins; most were suggested to be involved in host cell infections, implying that this parasite has well-developed mechanisms to infect different types of host cells and escape immune attack. ${ }^{107}$

Proteomics MS holds great potential for the discovery of biomarkers for diagnostic purposes in Chagas disease. The disease has a long incubation time extending to nearly three decades, during which the amastigote forms remain in the host. Therefore, identifying biomarkers derived from secreted parasite molecules in the serum would improve the prospects for a fast and reliable diagnostic assay. A comparative proteomic analysis of the secretomes of two T. cruzi strains, VD and CL Brener, revealed that over 350 of the proteins could be classified into multigene superfamilies, but 94 proteins did not correspond to any known superfamilies. ${ }^{108}$ Since these proteins were not reported from other T. cruzi strains, they could be potential biomarkers for infection by either the VD or the CL Brener strain. Two other strains, Y and YuYu, also showed distinct proteome profiles of the released vesicles that could be correlated with differences in their virulence and infectivity. ${ }^{109}$

Proteomics has also been employed for characterising the immune complexome of $T$. cruzi-infected patients. In a proteomic study on plasma from chronic Chagas disease patients, Ohyama et al. identified 39 antigens derived from $T$. cruzi and 114 autoantigens from the patients. ${ }^{110}$ In the same study, more than half of all the patients carried the surface protease GP63 and glucose-6-isomerase antigens derived from the pathogen, as well as six human autoantigens, namely, CD180 antigen, ceruloplasmin, fibrinogen beta chain, fibrinogen beta chain isoform 2 preprotein, isoform gammaA of the fibrinogen $\gamma$-chain and serum paraoxonase. Moreover, two factors, the human complement factor H-related protein 2 and the TS of T. cruzi, occurred most commonly in patients with symptomatic Chagas disease. Another study characterised the absence of peptide fragments of two proteins, apolipoprotein A-1 and fibronectin, in the serum of patients successfully treated with Bzn for congenital Chagas disease. ${ }^{111}$ Similarly, a proteomic study of two Brazilian strains showed that the expression profiles differed with respect to several proteins, including cruzipain, which is a key virulence factor, and this could be correlated to differences in infectivity determined through in vitro cellbased assays. ${ }^{112}$ The use of antisense oligonucleotides directed against TS, complement regulatory proteins or E64d in order to inhibit the activity of the cruzipain was found to be effective in reducing the virulence of a highly virulent strain in mouse models. ${ }^{113}$

The virulence of T. cruzi strains varies widely, and the correct identification of strains is beneficial for diagnostic and treatment purposes. The typing of strains has been accomplished by proteomic methods using tandem MS (MS/ MS) libraries. ${ }^{114}$ This method is independent of the genome data. Moreover, this method reliably identifies the DTU strains and is agnostic towards fragmentation techniques, gradient lengths during chromatographic steps or variations in sample 
preparation. Immunology techniques have been combined with proteomics in order to search for epitopes, which might propel the development of vaccines. In such an immunoproteome study, the calpain-like protein CAP5.5 was reported to be 23fold upregulated in the cardiac stage of Chagas disease, compared to the asymptomatic stage. ${ }^{115}$ In addition, immunoproteomics also led to the identification of the most immunogenic parasite proteins in mouse serum as pyruvate phosphate dikinase, Hsp-85, and $\beta$-tubulin. This work also demonstrated that recombinant $T$. cruzi $\beta$-tubulin was sufficient to immunize mice successfully against $T$. cruzi infection. ${ }^{116}$

\subsection{Posttranslational modifications in T. cruzi}

In addition to the protein phosphorylation PTM discussed in section 3.3, several other PTMs have been characterised by proteomics methods in T. cruzi. Selected studies are reviewed herein.

3.5.1 PTMs of T. cruzi histones. Although the regulation of gene expression in $T$. cruzi is predominantly posttranscriptional, increasing evidence suggests that epigenetic mechanisms also play a role in the parasite's life processes. ${ }^{117}$ For functional epigenomic studies to be possible, site-specific information on PTMs in the parasite histones needs to be obtained. In a large-scale proteomics study, Picchi et al. recently uncovered several PTMs including unconventional modifications such as N-terminal methylation, serine/threonine acetylation and non-canonical lysine acylations in T. cruzi histones. ${ }^{118}$ This study also identified 200 unique conserved sites for PTMs on T. cruzi histones, thus providing a data set that might prove useful for development of epigenetic drugs in the future. Another study compared the PTMs of histones in the epimastigote and trypomastigote stages; epimastigotes exhibited more histone modifications compared to trypomastigotes. ${ }^{119}$ Whereas in epimastigotes the predominant modifications were phosphorylation at serine 23 of H2B and methylation of lysine 76 of histone H3, C-terminal lysine acetylation of $\mathrm{H} 2 \mathrm{~A}$ and methylations of lysine 23 of histone $\mathrm{H} 3$ were the major modifications in the MT and TCDT stages. Owing to the importance of posttranslational histone acetylation for the regulation of various aspects of the T. cruzi cell cycle, the histone deacetylase inhibitor trichostatin A has been used in a quantitative proteomic study. ${ }^{120}$ This study showed that trichostatin A increases histone acetylation, suggesting that histone deacetylase inhibitors could be promising leads for drug development.

3.5.2 Protein glycosylation. Protein glycosylation, a common PTM of cell membrane proteins, involves enzymecatalysed addition of carbohydrate moieties to protein molecules. It may range from simple monosaccharide additions to highly branched complex polysaccharide modifications. The nature of the carbohydrate-amino acid chemical bond classifies the modification; the two major types are the $N$-linked and the $O$-linked glycosylations, which respectively feature the bonding of the carbohydrate moiety with the side-chain amide nitrogen atom of an asparagine residue and the side-chain hydroxyl oxygen atom of a serine/ threonine residue. Glycoproteins participate in many important processes of the parasite life cycle including host cell adhesion and invasion, and evading host immune responses. ${ }^{121,122}$ Therefore, they are considered promising drug targets in Chagas disease. Atwood III et al. performed affinity enrichment of $N$-linked glycoproteins from T. cruzi trypomastigotes using lectin columns. ${ }^{123}$ They used a combination of subcellular fractionation, stable isotope labelling of the glycan attachment site using $\mathrm{H}_{2}{ }^{18} \mathrm{O}$ and LCMS/MS to identify $36 \mathrm{~N}$-glycosylation sites in 29 parasite proteins, of which 11 were T. cruzi-specific. A more recent comprehensive glycoproteomics study employed glycanase treatment to identify 170 glycoproteins specific to the epimastigote stage, and 334 proteins specific to the trypomastigotes. ${ }^{124}$ Further, when the glycanase treatment was omitted and intact glycopeptides were analysed, 144 $\mathrm{N}$-linked members and $10 \mathrm{O}$-linked peptides were unique to epimastigotes, while for trypomastigotes the numbers in the same categories were 466 and 97 . It is likely that these stagespecific changes reflect the switching between invertebrate and vertebrate host cells during the life cycle.

Modification of the hydroxyl side chain of serine/threonine residues with a single unit of $\beta-N$-acetylglucosamine, termed $O$-linked $\beta$ - $N$-acetylglucosamine $(O$-GlcNAc) modification, has been implicated in many important cellular processes including the regulation of transcription and translation in higher eukaryotes. ${ }^{125}$ The $O$-GlcNAc modification is fundamentally different from other types of glycosylation: whereas the common $N$ - and $O$-glycosylations are relatively stable PTMs, the $O$-GlcNAc PTM is dynamic. It is catalysed by the enzyme $O$-GlcNAc transferase (OGT) and removed by $N$-acetyl- $\beta$-Dglucosamidase (O-GlcNAcase). In a recent study, TorresGutiérrez et al. reported the identification of the $O$-GlcNAc modification in T. cruzi proteins. ${ }^{126}$ They used the commercial "Click-iT O-GlcNAc enzymatic labeling system" "127 for enzymatically labelling and enriching the $O$-GlcNAc modified proteins from T. cruzi epimastigote lysates. On-bead digestion using a trypsin/Lys-C mixture followed by LC-MS/MS analysis of the eluted peptides identified 1271 putative O-GlcNAclated proteins. As the on-bead digestion protocol led to the retention of $O$-GlcNAc modified peptides on the resin, on-bead dephosphorylation and $\beta$-elimination steps prior to protein digestion were performed on a separate portion of the sample to release the modified peptides. This enabled the identification of six O-GlcNAc modification sites. Many of the putative $O$-GlcNAclated proteins identified have important biological roles including metabolic functions and stress adaptation.

3.5.3 SUMOylation. SUMOylation is a PTM that involves covalent attachment of small ubiquitin-like modifier (SUMO) proteins to other proteins via an isopeptide bond between a newly exposed C-terminal glycine residue of SUMO and sidechain amino group of lysine residues of acceptor proteins. It is a dynamic PTM and relies on the enzymes of the ubiquitin activating, conjugating, and ligating cascades for its formation and ubiquitin deconjugating enzymes for reversal. 
Despite the similarity with ubiquitination and reliance on the ubiquitination machinery, SUMOylation is not used as a protein degradation signal. Instead, a broad spectrum of cellular processes including transcription, nuclear-cytosolic transport, DNA damage responses, protein localisation and protein-protein interactions are influenced by SUMOylation. ${ }^{128}$ Using transgenic $T$. cruzi epimastigotes expressing a SUMO version with purification tags of human influenza hemagglutinin (HA) and hexahistidine (His6), Bayona et al. reported the first proteomics study of SuMOylation in T. cruzi. $^{129}$ The presence of the two purification tags allowed a tandem affinity enrichment of the SUMOylated proteins from the parasite lysate using $\mathrm{Ni}^{2+}$-NTA and anti-HA-agarose columns. Analysis of tryptic digests of the final eluents via two-dimensional LC-MS/MS revealed a total of 236 putative SUMOylated proteins. Nonspecific binding interactions, despite the use of tandem affinity purification, the lack of identification information about the modification sites and the lack of availability of a specific inhibitor compound for control experiments, make the validation of putative SUMOylation targets difficult. Nevertheless, independent biochemical assays validated metacaspase-3 from the putative target list as a genuine substrate of SUMOylation in the parasite.

\subsection{Protein-protein interactions in $T$. cruzi}

The combination of proteomics with an assessment of protein-protein interactions, termed "interactomics" forms part of a powerful approach to understanding cellular processes. ${ }^{130}$ The construction of mutant redox proteins and proteomics of the resulting complexes from pull-down assays with $T$. cruzi lysates have been used to identify proteins interacting with two major redox enzymes, tryparedoxins I and II (TcTXNI and TcTXNII). ${ }^{131,132}$ According to these studies, TcTXNI had 15 interacting protein partners, mainly with roles in redox metabolism and protein synthesis/ degradation, and TcTXNII had 16 partners involved in a variety of cellular functions. These two enzymes transfer electrons between trypanothione and peroxiredoxins, which is different from the thioredoxin-based electron transfer in mammals and may present novel targets for drug development. ${ }^{133}$ More recently, two TcI strains of T. cruzi, COL and SYL, were analysed by proteomics, which showed that the antioxidant network of the trypomastigotes was enhanced in comparison to that of a cultured clone. ${ }^{134}$

\subsection{Chemical proteomics in T. cruzi}

3.7.1 Target fishing and mechanism of action studies. The mechanism of action of benznidazole (Bzn), the major drug used in the treatment of Chagas disease, remain elusive. In order to identify the protein binding partners of the drug, Trochine et al. used a chemical proteomics approach. ${ }^{135}$ They first synthesised a Bzn derivative and immobilised that onto sepharose beads, which was then used for affinity chromatography with T. cruzi epimastigote lysates. The affinity-enriched proteins were resolved on a 1D gel and selected protein bands after tryptic digestion were analysed by MALDI-ToF/ToF MS/MS. A total of six proteins namely protein transport protein Sec23A, YXKO-related protein, $\alpha$-tubulin, $\beta$-tubulin, $\beta$-tubulin 1.9 and $T$. cruzi aldo-keto reductase (TcAKR) were identified. As TcAKR is related to enzymes previously reported to be associated with Bzn reductive activation, such as $T$. cruzi nitroreductase $(T c \mathrm{NTRI})^{136}$ and $T$. cruzi prostaglandin F2 $\alpha$ synthase/old yellow enzyme ( $T c \mathrm{OYE}){ }^{137}$ the study points to the possibility of reductive activation pathways for the drug action. However, the lack of competitive binding controls in this study makes arriving at definitive conclusions regarding the mechanism of action difficult. Resistance to Bzn has also been investigated by proteomics, leading to the identification of overexpressed proteins in one clone as calpain-like cysteine peptidase, hypothetical protein conserved $26 \mathrm{kDa}$, putative peptidase, peroxiredoxin, and tyrosine amino transferase, and in another as cyclophilin A, glutamate dehydrogenase, iron superoxide dismutase, and nucleoside diphosphate kinase. ${ }^{87}$

Napthoimidazoles derived from $\beta$-lapachone were shown to induce changes in the expression of a number of proteins in bloodstream trypomastigotes, including enzymes such as asparagine synthetase, arginine kinase, enolase, guanine deaminase, succinyl-CoA ligase, ATP synthase subunit B, and methionine sulfoxide reductase, thus paving the way for target-based drug design. ${ }^{138}$ In epimastigotes, proteomic methods allowed the elucidation of the mechanism of trypanocidal action following napthoimidazole treatment. ${ }^{88}$ Several pathways impacted were identified in this work, including energy metabolism, protein biosynthesis, chaperone modification, cytoskeletal assembly and ergosterol biosynthesis. Proteomics has also facilitated the study of the possible mechanism of action of trypanocidal natural products. For instance, following piplartine treatment, the expression of two antioxidant enzymes, tryparedoxin peroxidase (TXNPx) and methionine sulfoxide reductase (MSR), was upregulated in T. cruzi, suggesting that these enzymes could be potential therapeutic targets. ${ }^{139}$

3.7.2 Global profiling of substrates of NMT in $T$. cruzi. NMT inhibitors have been shown to inhibit the growth of $T$. cruzi parasites. ${ }^{140}$ Additionally, these inhibitors caused a dose-dependent decrease in the metabolic incorporation of an azide analogue of myristic acid into the myristoylome of the parasite. ${ }^{140}$ Roberts et al. recently extended this metabolic incorporation approach by combining it with LFQ- and SILAC-based quantitative proteomics MS in the presence and absence of their NMT inhibitor compound DDD85646. ${ }^{141}$ Their analyses identified $50 \mathrm{~N}$-myristoylated proteins in $T$. cruzi, representing $\sim 0.43$ to $0.46 \%$ of the parasite's total known proteome (Fig. 3B). Although the majority of the identified NMT substrates had unknown functions, a few proteins from the data set have important biological roles including intracellular transport, protein turnover and cell signalling. 


\section{Proteomics approaches in T. brucei}

\subsection{Human African trypanosomiasis: an introduction}

Human African trypanosomiasis (HAT), also known as African sleeping sickness, is caused by protozoa of the species Trypanosoma brucei (T. brucei). The disease is endemic in sub-Saharan Africa where it mainly affects poor rural communities; about 55 million people are at risk of contracting it. ${ }^{142}$ T. $\quad b$. gambiense accounts for the vast majority of cases of HAT in West and Central Africa, while $T$. b. rhodesiense accounts for the rest, mainly in East and Southern Africa. ${ }^{142}$ HAT is transmitted to humans via the bite of tsetse flies (Glossina), whereupon the parasites multiply and invade the blood and lymphatic system. The T. $b$. gambiense variant causes a slow-developing chronic disease in two stages; stage 1 (S1) is the hemolymphatic stage involving fever, headaches, inflammation of the lymph nodes, and simultaneous spleen and liver enlargement. ${ }^{143}$ Progression to stage 2 (S2), the nervous stage, is characterised by invasion of the central nervous system and neurological symptoms, which can lead to death. ${ }^{144,145}$ Patients with T. $b$. gambiense infections in $\mathrm{S} 1$ respond to pentamidine, but S2 patients need drugs that can cross the blood-brain barrier. S2 infection can be treated with a nifurtimox-eflornithine combination therapy (NECT) by invasive methods, which are challenging to execute in some areas. ${ }^{146}$ Both stages can be treated by fexinidazole, which was approved last year. ${ }^{147}$ However, accurate diagnosis of the stage of HAT will save lives and will need further research. For HAT infection caused by $T$. $b$. rhodesiense, only one drug, melarsoprol, is currently available. ${ }^{148}$ Development of more oral drugs will benefit the efforts to eliminate both forms of HAT.

\subsection{The $T$. brucei life cycle}

Inside the gut of the tsetse flies, the parasites exist as procyclic trypomastigotes and multiply by binary fission. When leaving the midgut, they differentiate into epimastigotes and migrate to the salivary glands, where a further differentiation to a metacyclic trypomastigote form occurs. When the vector bites the victim, the metacyclic trypomastigotes enter the human bloodstream and transform into bloodstream trypomastigotes, which rapidly multiply by binary fission, and reach various body fluids such as the spinal fluid and the lymph. In the bloodstream, the trypomastigotes proliferate in a long slender (LS) morphological form, which further differentiate, as the parasite-load in the bloodstream increases, into a short stumpy (SS) non-replicative form. The replication arrested SS forms are adapted for transmission to the tsetse flies, where they transform into procyclic promastigotes and continue the life cycle. The LS forms are responsible for the neurological complications arising in S2 of HAT. During this multistage life cycle, the parasite adapts by varying its proteome. ${ }^{149-151}$

\subsection{Characterising the life cycle stages and host-T. brucei} interactions

Global proteome profiling of procyclic and bloodstream stages of T. brucei with SILAC quantitative proteomics MS revealed that the procyclic forms have slower proteome turnover compared to the bloodstream stage; the fastest turnover rates were observed for cell cycle and cytokinesis proteins in both forms. ${ }^{152}$ Further, lower than average turnover rates were observed for mitochondrial and glycosomal proteins. ${ }^{152}$ Quantitative SILAC-based proteomics also helped to uncover the stage-specific expression of many proteins, for example, a DEAD box RNA helicase was found to be highly upregulated in the bloodstream form and is thought to be critical for parasite viability and cell cycle progression. ${ }^{153}$ SILAC-based proteomics MS also showed remodelling of the proteome during three different humaninfective forms and the final procyclic stage, with almost $30 \%$ of the proteome undergoing changes. ${ }^{154}$ More specifically, about $40 \%$ of the proteins in the plasma membrane, peroxisome, nucleus, mitochondria, microtubule, lysosome and glycosome are upregulated by 2 -fold or more while differentiating to the last bloodstream stage (short stumpy or SS). Quantitative proteomics enabled the tracking of over 4000 proteins during this transition and offered clues on how the parasites might evade host defence mechanisms. ${ }^{150}$

Evasion of the mammalian host immune defence is dependent on the antigenic variation of the variant surface glycoprotein (VSG). ${ }^{155}$ In the bloodstream form, the parasite surface is covered with around ten million copies of a single species of VSG and the sub-telomeric VSG genes are the major virulence determinants. The transcription of VSG at any time occurs from only one of the 20 sub-telomeric expression sites with switching to avoid lysis by the host adaptive immune response. Regulation of virulence gene expression by telomere structures is known in microbial pathogens, wherein those genes are often located next to the telomere. ${ }^{156}$ Differentiation of the bloodstream form into the procyclic form silences the transcription of the VSG genes. MS of the telomere protein complexes revealed that the complex composition differs between the two forms of the parasite. ${ }^{157}$ One novel telomereassociated protein, TelAP1, forms a complex with other telomeric proteins and participates in expression site silencing. Metabolomics studies have revealed that the myristate required for incorporation into the VSG can be synthesised by up to four distinct pathways. ${ }^{158}$ Indeed, multiple redundant biochemical pathways are used by many pathogens, and proteomics may help uncover which pathways and enzymes are involved in each stage.

In combination with subcellular fractionation techniques, proteomics enables biochemical characterisation of subcellular organelles. A nuclear proteome study of $T$. brucei in the procyclic form has demonstrated that over 750 proteins specifically enriched in the nuclear fraction. ${ }^{159}$ Motif enrichment analyses detected the presence of the KRxR sequence in many of these identified nuclear proteins, which is 
proposed to be the nuclear localisation signal for the Kinetoplastida class. Studies have also been carried out for characterising the proteome of the $T$. brucei lipid rafts. ${ }^{160,161}$ These are regions of the plasma membrane with high concentrations of cholesterol and glycosphingolipids and are postulated to be hubs that cluster virulence factors. ${ }^{162}$ The lipid raft proteome of the procyclic form contains proteins, of which functions of around $18 \%$ remain unknown. ${ }^{161}$ In addition, proteins with known or predicted functions also occurred, including Rab-like GTPases (part of the intra-flagellar transport protein or IFT complex), aquaporin, arginine kinase, and calcium dependent cysteine proteases. ${ }^{161}$ Arginine kinase is a flagellar protein, which plays an important role in infection, ${ }^{163}$ while aquaporin is a water channel protein which may also transport drugs, localising to the plasma membrane and implicated in the pentamidine resistance of the bloodstream form. ${ }^{164,165}$ A remarkable $60 \%$ of proteins are shared between the procyclic lipid raft proteome and the procyclic flagellar proteome. ${ }^{161}$ Superoxide dismutase (SOD), a glycosomal protein, was also found in the lipid raft. While its role in $T$. brucei is not yet elucidated, overexpression of the $T$. cruzi homologue causes enhanced susceptibility to the drugs Bzn and gentian violet in that organism. ${ }^{166}$

The potential number of coding sequences in the T. brucei genome is greater than previously thought; a transcriptomic study identified over 1100 sequences under 100 amino acid long, which map onto regions of the genome not containing annotated ORFs. ${ }^{167}$ Although 993 of these transcripts contain coding sequences corresponding to at least 25 amino acids, their functional expression remained unknown. Nevertheless, a combined application of bioinformatics methods and analysis of previous proteomics data sets successfully identified with high confidence 42 of these small proteins. ${ }^{167}$ More recently, Crozier et al. employed TMT-10plex quantitative proteomics MS for the analysis of the cell cycle of the procyclic form of $T$. brucei. ${ }^{168}$ They quantified the expression levels of over 5000 proteins across the cell cycle in the parasite. Off these, 384 proteins showed cell cycle regulated patterns of expression; 151 of these were hypothetical proteins of unknown function. About 40 of these are considered critical proteins for the parasite survival and therefore could be potential drug targets.

Using proteomics, over 60 human proteins were identified to vary in abundance in the serum, cerebrospinal fluid (CSF), urine and saliva between $T$. brucei-infected and healthy subjects. ${ }^{169}$ Two of them, neuroserpin from the CSF and moesin from urine, are considered potential biomarkers for HAT. ${ }^{169}$ Neuroserpin is predominantly expressed in regions such as the hippocampus and the caudate. ${ }^{170,171}$ Both those regions are near the choroid plexus, which constitutes a gap in the blood-brain barrier, and is suggested to be the site where the parasite enters the brain. ${ }^{172}$

Proteomic comparisons of infected and uninfected salivary glands of tsetse flies revealed that highly abundant $G$. morsitans proteins were downregulated in infected salivary glands. ${ }^{173}$ If this affects fly performance, it could lead to increased transmission, since it is known that when fly feeding is reduced, biting behaviour increases in order to reach satiety. ${ }^{174}$ In addition, other proteins advantageous to T. brucei were upregulated, including CamK, Serp-2, SUMO, eight distinct V-type ATPases and amino acid metabolismrelated proteins. ${ }^{173}$ CamK is a key regulator of stage-specific morphological differentiation in all parasitic protozoans, ${ }^{175}$ while Serp-2 plays a role in Plasmodium parasites to trigger a switch to transmissible sexual stages in mosquitoes. ${ }^{176}$ SUMO, responsible for SUMOylation discussed earlier in section 3.5.3, provides a quick way for changing the interaction partners and subcellular localisations of proteins, thus contributing to immune evasion. ${ }^{177}$ Downregulation of regulatory proteins occurred along with upregulation of the ubiquitin proteasome components, suggesting that protein translation/turnover increases leading to metacyclogenesis. ${ }^{173}$ Among proteins specific to $T$. brucei, suppression of regulatory proteins and transporters, and the upregulation of a high number of immunity, signal transduction and virulence-related proteins were observed.

\subsection{Proteomics of the T. brucei flagellum}

T. brucei is an extracellular parasite and all endocytosis and exocytosis are directed through a specific membrane region called the flagellar pocket, in which the majority of invariant surface proteins are considered to be localised. ${ }^{178}$ Genome mining for proteins with membrane-association is of limited utility since a large number of the predicted proteins are not likely to be surface-localised. A combination of biochemistry, proteomics and bioinformatics was used to characterise the surface proteome, which contained novel proteins, known flagellar pocket proteins and proteins required for parasite survival. ${ }^{179}$ Transporter-like proteins in the parasite were conserved in well-studied eukaryotes, but receptor-like proteins were mostly specific to trypanosomes. While the said study was able to support the view of a three-compartment cell surface, the mechanisms of protein sorting and targeting are still unclear. No simple localisation signals were found, and the protein architecture type did not correlate with domain localisation.

The flagellum plays important roles in $T$. brucei cell motility, parasite signalling and development, and parasite attachment during invasion of the salivary glands of the tsetse fly, but a sensory role has also been postulated. ${ }^{180}$ Proteomic analysis of the intact flagellum detected over 200 proteins not previously linked to flagella; out of these, a 14-33 protein and eight novel proteins termed FLAM (flagellar member) were experimentally validated. ${ }^{181}$ Cardiolipin is a mitochondrial and bacterial lipid important for the stability of electron transport complexes. ${ }^{182}$ Unlike other eukaryotes, the Apicomplexa (which include the malaria parasites) and the Euglenozoa (which include the trypanosomatids) harbour bacterial-type cardiolipin synthases. ${ }^{183}$ This difference between T. brucei and its hosts, and the fact that it is essential in T. brucei make cardiolipin synthesis an attractive target for therapeutic interventions. Combining the use of 
knockout mutants for cardiolipin synthase, SILAC and MS, a number of proteins that bind cardiolipin, termed cardiolipindependent proteins (CLDP), were discovered. ${ }^{184}$

\subsection{The phosphoproteome of $T$. brucei}

Global phosphoproteomics in T. brucei enabled quantitative comparisons between the procyclic and bloodstream forms and revealed significant differences in phosphorylation patterns between the two forms. ${ }^{185}$ In the procyclic form, a number of proteins exhibited upregulation of specific phosphorylation sites, including a C14-sterol reductase involved in ergosterol synthesis, a ubiquitin carboxy-terminal hydrolase and PAD2, a carboxylic acid transporter with possible roles in cell differentiation. The bloodstream form upregulates the phosphorylation of other proteins, for example, the RNA recognition motif protein RBP10, which could promote bloodstream mRNA expression. Certain groups of proteins such as ZFPs (zinc finger proteins) and RBPs (RNA binding proteins) which are expected to participate in the posttranscriptional regulation of gene expression were also subject to regulated phosphorylation.

Tyrosine-specific phosphoproteomics in T. brucei procyclic forms using a combination of immunoaffinity purification and LC-MS/MS identified over 30 tyrosine-specific phosphorylated proteins involved in protein synthesis, RNA metabolism, energy metabolism, and kinases, including 19 protein kinases and two metabolic kinases. ${ }^{186}$ In the CMG kinase group, 11 candidates were found to be putative homologues of Leishmania MAPK (mitogen-activated protein kinase). The highly conserved TXY motifs in the activation loops were found fully phosphorylated in eight of the putative TbMAPKs, suggesting that they were activated in the procyclic form of $T$. brucei. ${ }^{186}$ The phosphoproteome of the bloodstream form showed that phosphorylated serine/ threonine kinases (STE kinases) were present, suggesting signal transduction via MAPK. ${ }^{187}$ Moreover, the same study indicated that phosphorylation of certain proteins is not stage-specific, since all three CRK isoforms were phosphorylated on the same tyrosine residue. Tyrosinephosphorylated proteins in both bloodstream and procyclic forms were concentrated in the nucleolus and the cytoskeletal structures (basal body and flagellum), lending support to the notion that the function of signalling molecules is governed by their subcellular localisation. The localisation pattern also underscores the differences between this parasite and higher eukaryotes, such as humans, since kinetoplastids are among the most ancient eukaryotes, probably older than even fungi. ${ }^{19}$ Further, the localisation of glycogen synthase kinase 3 (GSK3) in the flagellum, along with identified phosphorylation sites in its active loop, indicates that this kinase is active in T. brucei, and suggests that tyrosine phosphorylation may participate in the regulation of flagellum formation and basal body segregation. ${ }^{187}$ In fact, many organelles such as the basal body, the flagellum, the mitochondrion and the kinetoplast (mitochondrial DNA network) are present in a single copy and must be segregated and duplicated during cell division. Therefore, understanding organelle segregation and duplication could be important for drug development.

Tyrosine-phosphorylated GSK3 has been previously shown to be essential for flagella assembly and maintenance in Chlamydomonas reinhardtii. ${ }^{188}$ Therefore, GSK3 possibly plays a similar role in $T$. brucei. The $T$. brucei genome lacks tyrosine kinase-like kinases, $\mathrm{G}$ protein-coupled receptors and proteins with phosphotyrosine-binding domains, but phosphorylation of the members of the STE kinase family and a homologue of the ERK1 from the amoeba Dictyostelium discoideum indicates the presence of a putative ERK1/2 signalling pathway in $T$. brucei. $^{187}$ The mechanism or regulation is still unknown and likely novel. Additionally, about a quarter of the manually validated kinase sites were not predicted by bioinformatics, suggesting that $T$. brucei may contain kinases with novel substrate specificity and previously unrecognised motifs. ${ }^{187}$

\subsection{Chemical proteomics in T. brucei}

4.6.1 Target profiling of oxaboroles. The oxaborole compound SCYX-7158 is currently in clinical trials in patients with S1 and S2 HAT caused by T. b. gambiense. ${ }^{189}$ However, its mechanism of action remains unknown. Jones et al. employed a chemical proteomics approach for identifying the target proteins of the drug that could be involved in the mechanism of action. ${ }^{190}$ They first synthesised an oxaborole derivative and immobilised it onto paramagnetic beads for performing target-fishing experiments. In one set of experiments, SILAC heavy and light isotope labelled $T$. brucei cell lysates were incubated with the beads in the presence and absence respectively of the parent oxaborole inhibitor pre-incubated in the lysate. As the dissolved inhibitor compound in the lysate may outcompete target engagement(s) of the immobilised compound, specific targets may produce a lowered heavy/light ratio whilst that of the non-specific binders remains unaffected. In a second set of experiments, inactive beads without the oxaborole immobilisation were used as a control against the oxaborole-immobilised beads for pull-down experiments using SILAC heavy and light isotope labelled lysates, respectively. In this case also, the non-specific binders may remain unaffected by the SILAC and may generate a $\log _{2}$ (heavy/light) ratio of zero, whilst that of the specific binders may be less than zero. By comparing the results from the two approaches, they identified 13 common proteins that generated more than four-fold selectivity against non-specific binders, indicating polypharmacology for the oxaborole activity. Among the identified proteins were metabolic proteins involved in glycolysis, the tricarboxylic acid cycle, gluconeogenesis, proteolysis and branched chain amino acid metabolism, as well as hypothetical proteins and proteins linked to mRNA splicing and mitochondrial biogenesis. This coupled with the difficulty in generating resistant mutants strongly suggested that the mechanism of action is not specific to one target (polypharmacology). 
4.6.2 N-Terminal myristoylation. A landmark study of Frearson et al. validated T. brucei NMT as a promising therapeutic target for HAT. ${ }^{191}$ Later, by using an alkynetagged myristic acid analogue, Price et al. developed a metabolic labelling approach for assessing $N$-myristoylation of a small GTPase protein $T$. brucei Arf-like protein 6 (TbARL6). ${ }^{192}$ In this case, a click reaction with a fluorescent azide dye permitted in-gel fluorescence imaging of the labelled TbARL6 protein, confirming its myristoylation. Wright et al. extended this metabolic tagging approach by combining it with LFQ proteomics MS in both insect and bloodstream stages of the parasite (Fig. 3C). ${ }^{193}$ The study identified 91 and 101 putative $N$-myristoylated proteins in the insect and bloodstream stages, respectively. Approximately half of the identified proteins possessed the N-terminal glycine residue or "MG signature motif" required for the NMT-mediated myristoylation. The non-MG enriched proteins were predominantly GPI-anchored and $S$-acylated (e.g. palmitoylation at cysteine residues). In the bloodstream parasites, NMT inhibitor treatment specifically reduced the incorporation of the alkyne myristic acid analogue into the NMT substrates but not the GPI-anchored proteins, clearly indicating the target specificity of the inhibitor.

\subsection{Nascent DNA proteomics}

The trypanosomatids exhibit unusual DNA replication properties, such as highly divergent origin replication complex (ORC) subunits, an apparent absence of many replication factor homologues and considerably fewer origins of replication than well-studied eukaryotes. ${ }^{194,195}$ The application of iPOND (isolation of proteins on nascent DNA) technology to T. brucei identified proteins involved in the core replication machinery, transcription, chromatin organisation, and DNA repair that were enriched near an unperturbed active replication fork. About 100 of those proteins were annotated as performing "unknown functions" and potentially specific to trypanosome replication. Follow-up studies on two proteins annotated as Tb927.10.7990 (replication factor C subunit) and Tb927.3.5370 (protein of unknown function) revealed that Tb927.10.7990 is essential since its silencing resulted in a growth defect in procyclic cells. Apart from antigenic variation, unusual replication and posttranscriptional regulation, trypanosomes also display other features such as polycistronic transcription without classical promoters and transcription of certain abundant proteins by RNA polymerase I, underlining the importance of unique nuclear processes in their biology.

\section{Conclusions}

Mass spectrometry-based proteomics has evolved as a powerful technique for studying various aspects of the life cycle of the protozoan parasites causing NTDs. The lack of transcriptional control of gene expression in Tritryps makes protein-based functional studies particularly suitable in these organisms. The differentiation process or life cycle changes is a peculiar aspect of the protozoan biology, the molecular mechanisms of which are largely unknown, despite decades of research using conventional methods of parasitology or biological research methods in general. Unravelling the molecular processes associated with life cycle differentiation holds the keys to understanding the mechanisms of virulence and infectivity. Proteomics MS has so far facilitated the measurement of the differential expression of several hundreds of proteins during the various life cycle stages of the three parasite genera reviewed herein. It is generally assumed that protein interactions in the differentially modulated proteomes detected in the life cycle stages are responsible for the observed phenotypic changes. Deconvoluting the molecular interactions and accurately annotating their functions within the modulated proteome will take significant in silico studies and follow-up biochemical experimental studies. However, a caveat is that the original measurements of the proteome were not made in real-time, as in during the transition of one life cycle stage to another but rather afterwards. Therefore, the currently available proteomics data sets that enabled the differential comparison of life cycle changes, although highly useful, many not have accurately captured all the dynamic perturbations in the proteome occurring at the actual timescale of the differentiation process. Additionally, the protein expression difference is not the only parameter that determines protein function. Rather, a large repertoire of protein modifications including PTMs and changes in the activity of enzymes and dynamic changes in the subcellular localisation of proteins during these processes must be playing important roles. Some progress in this direction has already been accomplished thanks to the recent developments in PTM enrichment strategies and advancements in MS instrumentation. For instance, large-scale profiling of important post- and/or co-translational modifications such as phosphorylation, glycosylation, $\mathrm{N}$-terminal myristoylation and SUMOylation was carried out in the protozoans. Some of the enzymes responsible for these modifications have already been validated as therapeutic targets. Accurate profiling of the target engagement and off-target profiling of pharmacologically active compounds as well as elucidating their mechanisms of action is another stronghold of proteomics MS. A relatively new area termed chemical proteomics that uses a combination of synthetic chemistry tools and quantitative proteomics MS technologies has evolved towards this end. This review has touched upon recent developments in all these areas where proteomics has played important roles.

\section{Conflicts of interest}

The authors declare no conflicts of interest.

\section{Acknowledgements}

KK acknowledges funding from the MRC-Global Challenges Research Fund (Grant number: MR/P027987/1A). AP acknowledges the Thomas H. Gosnell School of Life Sciences at RIT. 


\section{Notes and references}

1 M. C. Field, D. Horn, A. H. Fairlamb, M. A. J. Ferguson, D. W. Gray, K. D. Read, M. De Rycker, L. S. Torrie, P. G. Wyatt, S. Wyllie and I. H. Gilbert, Nat. Rev. Microbiol., 2017, 15, 217-231.

2 P. J. Hotez, D. H. Molyneux, A. Fenwick, J. Kumaresan, S. E. Sachs, J. D. Sachs and L. Savioli, N. Engl. J. Med., 2007, 357, 1018-1027.

3 https://www.who.int/neglected_diseases/news/WHOpublishes-guidelines-treatment-sleeping-sickness/en/, (accessed 01 May 2020).

4 G. B. D. Disease, I. Injury and C. Prevalence, Lancet, 2017, 390, 1211-1259.

5 B. Liese, M. Rosenberg and A. Schratz, Lancet, 2010, 375, 67-76.

6 S. L. Reed and J. H. McKerrow, Clin. Infect. Dis., 2018, 67, 323-326.

7 S. Patterson and S. Wyllie, Trends Parasitol., 2014, 30, 289-298.

8 R. Viotti, B. Alarcon de Noya, T. Araujo-Jorge, M. J. Grijalva, F. Guhl, M. C. Lopez, J. M. Ramsey, I. Ribeiro, A. G. Schijman, S. Sosa-Estani, F. Torrico, J. Gascon and N. Latin American Network for Chagas Disease, Antimicrob. Agents Chemother., 2014, 58, 635-639.

9 S. Sundar, A. Singh, M. Rai, V. K. Prajapati, A. K. Singh, B. Ostyn, M. Boelaert, J. C. Dujardin and J. Chakravarty, Clin. Infect. Dis., 2012, 55, 543-550.

10 M. L. den Boer, J. Alvar, R. N. Davidson, K. Ritmeijer and M. Balasegaram, Expert Opin. Emerging Drugs, 2009, 14, 395-410.

11 M. Mueller, K. Ritmeijer, M. Balasegaram, Y. Koummuki, M. R. Santana and R. Davidson, Trans. R. Soc. Trop. Med. Hyg., 2007, 101, 19-24.

12 J. Shendure and E. Lieberman Aiden, Nat. Biotechnol, 2012, 30, 1084-1094.

13 P. D. Wes, I. R. Holtman, E. W. Boddeke, T. Moller and B. J. Eggen, Glia, 2016, 64, 197-213.

14 M. I. McCarthy and D. G. MacArthur, Genome Biol., 2017, 18, 20.

15 B. Schwanhausser, D. Busse, N. Li, G. Dittmar, J. Schuchhardt, J. Wolf, W. Chen and M. Selbach, Nature, 2011, 473, 337-342.

16 S. P. Gygi, Y. Rochon, B. R. Franza and R. Aebersold, Mol. Cell. Biol., 1999, 19, 1720-1730.

17 A. Subramanian and R. R. Sarkar, Genomics, 2015, 106, 232-241.

18 S. M. Beverley, Cell, 1996, 87, 787-789.

19 A. P. Fernandes, K. Nelson and S. M. Beverley, Proc. Natl. Acad. Sci. U. S. A., 1993, 90, 11608-11612.

20 C. Clayton and M. Shapira, Mol. Biochem. Parasitol., 2007, 156, 93-101.

21 S. Haile and B. Papadopoulou, Curr. Opin. Microbiol., 2007, 10, 569-577.

22 S. Kramer, Mol. Biochem. Parasitol., 2012, 181, 61-72.

23 L. J. Jensen, R. Gupta, N. Blom, D. Devos, J. Tamames, C. Kesmir, H. Nielsen, H. H. Staerfeldt, K. Rapacki, C.
Workman, C. A. Andersen, S. Knudsen, A. Krogh, A. Valencia and S. Brunak, J. Mol. Biol., 2002, 319, 1257-1265.

24 P. J. Myler and K. D. Stuart, Curr. Opin. Microbiol., 2000, 3, 412-416.

25 S. Hanash, Nature, 2003, 422, 226-232.

26 G. Marko-Varga and T. E. Fehniger, J. Proteome Res., 2004, 3, 167-178.

27 M. Kavallaris and G. M. Marshall, Med. J. Aust., 2005, 182, 575-579.

28 Z. Zhang, S. Wu, D. L. Stenoien and L. Pasa-Tolic, Annu. Rev. Anal. Chem., 2014, 7, 427-454.

29 B. F. Cravatt, G. M. Simon and J. R. Yates, 3rd, Nature, 2007, 450, 991-1000.

30 R. C. Wilson and J. A. Doudna, Annu. Rev. Biophys., 2013, 42, 217-239.

31 X. Wu, M. A. Hasan and J. Y. Chen, J. Theor. Biol., 2014, 362, 44-52.

32 M. Frantzi, A. Latosinska and H. Mischak, Proteomics: Clin. Appl., 2019, 13, e1800087.

33 P. E. Geyer, L. M. Holdt, D. Teupser and M. Mann, Mol. Syst. Biol., 2017, 13, 942.

34 S. Burza, S. L. Croft and M. Boelaert, Lancet, 2018, 392, 951-970.

35 J. Alvar, I. D. Velez, C. Bern, M. Herrero, P. Desjeux, J. Cano, J. Jannin, M. den Boer and WHO L. C. Team, PLoS One, 2012, 7, e35671.

36 S. Sundar and P. L. Olliaro, Ther. Clin. Risk Manage., 2007, 3, 733-740.

37 D. H. Kim, H. J. Chung, J. Bleys and R. F. Ghohestani, PLoS Neglected Trop. Dis., 2009, 3, e381.

38 S. Sundar and J. Chakravarty, Int. J. Environ. Res. Public Health, 2010, 7, 4267-4277.

39 E. Handman, G. F. Mitchell and J. W. Goding, J. Immunol., 1981, 126, 508-512.

40 E. Handman, R. E. Hocking, G. F. Mitchell and T. W. Spithill, Mol. Biochem. Parasitol., 1983, 7, 111-126.

41 N. G. Saravia, M. A. Gemmell, S. L. Nance and N. L. Anderson, Clin. Chem., 1984, 30, 2048-2052.

42 P. G. Nugent, S. A. Karsani, R. Wait, J. Tempero and D. F. Smith, Mol. Biochem. Parasitol., 2004, 136, 51-62.

43 Z. Mojtahedi, J. Clos and E. Kamali-Sarvestani, Exp. Parasitol., 2008, 119, 422-429.

44 W. Moreira, D. Légaré, G. Racine, G. Roy and M. Ouellette, EuPa Open Proteomics, 2014, 4, 171-183.

45 P. Pescher, T. Blisnick, P. Bastin and G. F. Spath, Cell. Microbiol., 2011, 13, 978-991.

46 N. Gupta, N. Goyal and A. K. Rastogi, Trends Parasitol., 2001, 17, 150-153.

47 J. Walker, R. Gongora, J. J. Vasquez, J. Drummelsmith, R. Burchmore, G. Roy, M. Ouellette, M. A. Gomez and N. G. Saravia, Mol. Biochem. Parasitol., 2012, 183, 166-176.

48 D. A. Goyeneche-Patino, L. Valderrama, J. Walker and N. G. Saravia, Antimicrob. Agents Chemother., 2008, 52, 4503-4506.

49 R. L. Krauth-Siegel, S. K. Meiering and H. Schmidt, Biol. Chem., 2003, 384, 539-549. 
50 X. Wang, S. Shen, S. S. Rasam and J. Qu, Mass Spectrom. Rev., 2019, 38, 461-482.

51 J. Griss, F. Stanek, O. Hudecz, G. Durnberger, Y. PerezRiverol, J. A. Vizcaino and K. Mechtler, J. Proteome Res., 2019, 18, 1477-1485.

52 A. Thompson, J. Schafer, K. Kuhn, S. Kienle, J. Schwarz, G. Schmidt, T. Neumann, R. Johnstone, A. K. Mohammed and C. Hamon, Anal. Chem., 2003, 75, 1895-1904.

53 S. Wiese, K. A. Reidegeld, H. E. Meyer and B. Warscheid, Proteomics, 2007, 7, 340-350.

54 S. E. Ong, B. Blagoev, I. Kratchmarova, D. B. Kristensen, H. Steen, A. Pandey and M. Mann, Mol. Cell. Proteomics, 2002, 1, 376-386.

55 J. L. Hsu and S. H. Chen, Philos. Trans. R. Soc., A, 2016, 374, 20150364.

56 E. de Rezende, R. Kawahara, M. S. Pena, G. Palmisano and B. S. Stolf, PLoS Neglected Trop. Dis., 2017, 11, e0006090.

57 J. P. Menezes, T. F. Almeida, A. L. Petersen, C. E. Guedes, M. S. Mota, J. G. Lima, L. C. Palma, G. A. Buck, M. A. Krieger, C. M. Probst and P. S. Veras, Microbes Infect., 2013, 15, 579-591.

58 A. K. Singh, R. K. Pandey, J. L. Siqueira-Neto, Y. J. Kwon, L. H. Freitas-Junior, C. Shaha and R. Madhubala, Infect. Immun., 2015, 83, 1853-1868.

59 A. Isnard, J. G. Christian, M. Kodiha, U. Stochaj, W. R. McMaster and M. Olivier, PLoS Pathog., 2015, 11, e1004776.

60 K. Chandramouli and P. Y. Qian, Hum. Genomics Proteomics, 2009, 2009, 239204.

61 F. Conceicao-Silva and F. N. Morgado, Front. Cell. Infect. Microbiol., 2019, 9, 330.

62 M. A. Lynn, A. K. Marr and W. R. McMaster, J. Proteomics, 2013, 82, 179-192.

63 D. Nandan, S. A. Thomas, A. Nguyen, K. M. Moon, L. J. Foster and N. E. Reiner, PLoS One, 2017, 12, e0170068.

64 L. M. de Pablos, T. R. Ferreira, A. A. Dowle, S. Forrester, E. Parry, K. Newling and P. B. Walrad, Mol. Cell. Proteomics, 2019, 18, 1271-1284.

65 J. Wang, L. Gao, Y. M. Lee, K. A. Kalesh, Y. S. Ong, J. Lim, J. E. Jee, H. Sun, S. S. Lee, Z. C. Hua and Q. Lin, Pharmacol. Ther., 2016, 162, 10-22.

66 M. H. Wright and S. A. Sieber, Nat. Prod. Rep., 2016, 33, 681-708.

67 M. R. Luth, P. Gupta, S. Ottilie and E. A. Winzeler, ACS Infect. Dis., 2018, 4, 301-314.

68 S. Wyllie, M. Thomas, S. Patterson, S. Crouch, M. De Rycker, R. Lowe, S. Gresham, M. D. Urbaniak, T. D. Otto, L. Stojanovski, F. R. C. Simeons, S. Manthri, L. M. MacLean, F. Zuccotto, N. Homeyer, H. Pflaumer, M. Boesche, L. Sastry, P. Connolly, S. Albrecht, M. Berriman, G. Drewes, D. W. Gray, S. Ghidelli-Disse, S. Dixon, J. M. Fiandor, P. G. Wyatt, M. A. J. Ferguson, A. H. Fairlamb, T. J. Miles, K. D. Read and I. H. Gilbert, Nature, 2018, 560, 192-197.

69 H. Franken, T. Mathieson, D. Childs, G. M. Sweetman, T. Werner, I. Togel, C. Doce, S. Gade, M. Bantscheff, G. Drewes, F. B. Reinhard, W. Huber and M. M. Savitski, Nat. Protoc., 2015, 10, 1567-1593.
70 D. Martinez Molina, R. Jafari, M. Ignatushchenko, T. Seki, E. A. Larsson, C. Dan, L. Sreekumar, Y. Cao and P. Nordlund, Science, 2013, 341, 84-87.

71 R. Jafari, H. Almqvist, H. Axelsson, M. Ignatushchenko, T. Lundback, P. Nordlund and D. Martinez Molina, Nat. Protoc., 2014, 9, 2100-2122.

72 V. Corpas-Lopez, S. Moniz, M. Thomas, R. J. Wall, L. S. Torrie, D. Zander-Dinse, M. Tinti, S. Brand, L. Stojanovski, S. Manthri, I. Hallyburton, F. Zuccotto, P. G. Wyatt, M. De Rycker, D. Horn, M. A. J. Ferguson, J. Clos, K. D. Read, A. H. Fairlamb, I. H. Gilbert and S. Wyllie, ACS Infect. Dis., 2019, 5, 111-122.

73 N. G. Jones, C. M. C. Catta-Preta, A. Lima and J. C. Mottram, ACS Infect. Dis., 2018, 4, 467-477.

74 M. H. Wright, D. Paape, E. M. Storck, R. A. Serwa, D. F. Smith and E. W. Tate, Chem. Biol., 2015, 22, 342-354.

75 M. Meldal and C. W. Tornoe, Chem. Rev., 2008, 108, 2952-3015.

76 S. Besteiro, R. A. Williams, L. S. Morrison, G. H. Coombs and J. C. Mottram, J. Biol. Chem., 2006, 281, 11384-11396.

77 N. S. Carter, P. A. Yates, S. K. Gessford, S. R. Galagan, S. M. Landfear and B. Ullman, Mol. Microbiol., 2010, 78, 92-107.

78 J. L. Martin, P. A. Yates, R. Soysa, J. F. Alfaro, F. Yang, K. E. Burnum-Johnson, V. A. Petyuk, K. K. Weitz, D. G. Camp, 2nd, R. D. Smith, P. A. Wilmarth, L. L. David, G. Ramasamy, P. J. Myler and N. S. Carter, PLoS Pathog., 2014, 10, e1003938.

79 D. C. Dieterich, A. J. Link, J. Graumann, D. A. Tirrell and E. M. Schuman, Proc. Natl. Acad. Sci. U. S. A., 2006, 103, 9482-9487.

80 K. Kalesh and P. W. Denny, PLoS Neglected Trop. Dis., 2019, 13, e0007651.

81 J. A. Perez-Molina and I. Molina, Lancet, 2018, 391, 82-94.

82 M. C. P. Nunes, A. Beaton, H. Acquatella, C. Bern, A. F. Bolger, L. E. Echeverria, W. O. Dutra, J. Gascon, C. A. Morillo, J. Oliveira-Filho, A. L. P. Ribeiro, J. A. Marin-Neto, E. American Heart Association Rheumatic Fever, Y. Kawasaki Disease Committee of the Council on Cardiovascular Disease in the, C. Council on, N. Stroke and C. Stroke, Circulation, 2018, 138, e169-e209.

83 B. Zingales, Acta Trop., 2018, 184, 38-52.

84 B. Zingales, R. G. Araujo, M. Moreno, J. Franco, P. H. Aguiar, S. L. Nunes, M. N. Silva, S. Ienne, C. R. Machado and A. Brandao, Mem. Inst. Oswaldo Cruz, 2015, 110, 433-444.

85 A. M. Macedo, C. R. Machado, R. P. Oliveira and S. D. Pena, Mem. Inst. Oswaldo Cruz, 2004, 99, 1-12.

86 J. A. Atwood, 3rd, D. B. Weatherly, T. A. Minning, B. Bundy, C. Cavola, F. R. Opperdoes, R. Orlando and R. L. Tarleton, Science, 2005, 309, 473-476.

87 H. M. Andrade, S. M. Murta, A. Chapeaurouge, J. Perales, P. Nirde and A. J. Romanha, J. Proteome Res., 2008, 7, 2357-2367.

88 R. F. Menna-Barreto, D. G. Beghini, A. T. Ferreira, A. V. Pinto, S. L. De Castro and J. Perales, J. Proteomics, 2010, 73, 2306-2315. 
89 R. L. Goncalves, R. F. Barreto, C. R. Polycarpo, F. R. Gadelha, S. L. Castro and M. F. Oliveira, J. Bioenerg. Biomembr., 2011, 43, 651-661.

90 C. A. Pereira, G. D. Alonso, M. C. Paveto, A. Iribarren, M. L. Cabanas, H. N. Torres and M. M. Flawia, J. Biol. Chem., 2000, 275, 1495-1501.

91 A. Parodi-Talice, R. Duran, N. Arrambide, V. Prieto, M. D. Pineyro, O. Pritsch, A. Cayota, C. Cervenansky and C. Robello, Int. J. Parasitol., 2004, 34, 881-886.

92 B. K. Kubata, Z. Kabututu, T. Nozaki, C. J. Munday, S. Fukuzumi, K. Ohkubo, M. Lazarus, T. Maruyama, S. K. Martin, M. Duszenko and Y. Urade, J. Exp. Med., 2002, 196, 1241-1251.

93 G. V. Brunoro, M. A. Caminha, A. T. Ferreira, V. Leprevost Fda, P. C. Carvalho, J. Perales, R. H. Valente and R. F. Menna-Barreto, J. Proteomics, 2015, 115, 58-65.

94 A. D. Magalhaes, S. Charneau, J. Paba, R. A. Guercio, A. R. Teixeira, J. M. Santana, M. V. Sousa and C. A. Ricart, Proteome Sci., 2008, 6, 24.

95 E. S. Nakayasu, T. J. Sobreira, R. Torres, Jr., L. Ganiko, P. S. Oliveira, A. F. Marques and I. C. Almeida, J. Proteome Res., 2012, 11, 237-246.

96 A. Parodi-Talice, V. Monteiro-Goes, N. Arrambide, A. R. Avila, R. Duran, A. Correa, B. Dallagiovanna, A. Cayota, M. Krieger, S. Goldenberg and C. Robello, J. Mass Spectrom., 2007, 42, 1422-1432.

97 J. C. Amorim, M. Batista, E. S. da Cunha, A. C. R. Lucena, C. V. P. Lima, K. Sousa, M. A. Krieger and F. K. Marchini, Sci. Rep., 2017, 7, 9899.

98 A. C. R. Lucena, J. C. Amorim, C. V. de Paula Lima, M. Batista, M. A. Krieger, L. M. F. de Godoy and F. K. Marchini, Cell Stress Chaperones, 2019, 24, 927-936.

99 C. C. Avila, S. N. Mule, L. Rosa-Fernandes, R. Viner, M. J. Barison, A. G. Costa-Martins, G. S. Oliveira, M. M. G. Teixeira, C. R. F. Marinho, A. M. Silber and G. Palmisano, Genes, 2018, 9, 413.

100 R. M. Queiroz, S. Charneau, S. C. Mandacaru, V. Schwammle, B. D. Lima, P. Roepstorff and C. A. Ricart, Mol. Cell. Proteomics, 2014, 13, 3457-3472.

101 E. Rondinelli, R. Silva, J. F. Carvalho, C. M. de Almeida Soares, E. F. de Carvalho and F. T. de Castro, Exp. Parasitol., 1988, 66, 197-204.

102 R. L. Kessler, V. T. Contreras, N. P. Marliere, A. Aparecida Guarneri, L. H. Villamizar Silva, G. Mazzarotto, M. Batista, V. T. Soccol, M. A. Krieger and C. M. Probst, Mol. Microbiol., 2017, 104, 712-736.

103 E. M. Cordero, E. S. Nakayasu, L. G. Gentil, N. Yoshida, I. C. Almeida and J. F. da Silveira, J. Proteome Res., 2009, 8, 3642-3652.

104 H. Soblik, A. E. Younis, M. Mitreva, B. Y. Renard, M. Kirchner, F. Geisinger, H. Steen and N. W. Brattig, Mol. Cell. Proteomics, 2011, 10, M111 010157.

105 N. O. Martins, R. T. Souza, E. M. Cordero, D. C. Maldonado, C. Cortez, M. M. Marini, E. R. Ferreira, E. Bayer-Santos, I. C. Almeida, N. Yoshida and J. F. Silveira, PLoS Neglected Trop. Dis., 2015, 9, e0004216.
106 E. Bayer-Santos, C. Aguilar-Bonavides, S. P. Rodrigues, E. M. Cordero, A. F. Marques, A. Varela-Ramirez, H. Choi, N. Yoshida, J. F. da Silveira and I. C. Almeida, J. Proteome Res., 2013, 12, 883-897.

107 R. M. Queiroz, C. A. Ricart, M. O. Machado, I. M. Bastos, J. M. de Santana, M. V. de Sousa, P. Roepstorff and S. Charneau, Front. Chem., 2016, 4, 42.

108 J. Y. Brossas, J. E. N. Gulin, M. M. C. Bisio, M. Chapelle, C. Marinach-Patrice, M. Bordessoules, G. Palazon Ruiz, J. Vion, L. Paris, J. Altcheh and D. Mazier, PLoS One, 2017, 12, e0185504.

109 K. S. Ribeiro, C. I. Vasconcellos, R. P. Soares, M. T. Mendes, C. C. Ellis, M. Aguilera-Flores, I. C. de Almeida, S. Schenkman, L. K. Iwai and A. C. Torrecilhas, J. Extracell. Vesicles, 2018, 7, 1463779.

110 K. Ohyama, N. T. Huy, H. Yoshimi, N. Kishikawa, J. E. Nishizawa, Y. Roca, R. J. Revollo Guzman, F. U. Velarde, N. Kuroda and K. Hirayama, Parasite Immunol., 2016, 38, 609-617.

111 E. Ruiz-Lancheros, A. Rasoolizadeh, E. Chatelain, F. GarciaBournissen, S. Moroni, G. Moscatelli, J. Altcheh and M. Ndao, Open Forum Infect. Dis., 2018, 5, ofy236.

112 S. A. Kikuchi, C. L. Sodre, D. E. Kalume, C. G. Elias, A. L. Santos, M. de Nazare Soeiro, M. Meuser, A. Chapeaurouge, J. Perales and O. Fernandes, Exp. Parasitol., 2010, 126, 540-551.

113 J. San Francisco, I. Barria, B. Gutierrez, I. Neira, C. Munoz, H. Sagua, J. E. Araya, J. C. Andrade, A. Zailberger, A. Catalan, F. Remonsellez, J. L. Vega and J. Gonzalez, Microbes Infect., 2017, 19, 55-61.

114 G. S. de Oliveira, R. Kawahara, L. Rosa-Fernandes, S. N. Mule, C. C. Avila, M. M. G. Teixeira, M. R. Larsen and G. Palmisano, PLoS Neglected Trop. Dis., 2018, 12, e0006351.

115 M. A. Caminha, V. M. B. de Lorena, W. de Oliveira Junior, J. Perales, P. C. Carvalho, D. B. Lima, M. Cavalcanti, S. M. Martins, R. H. Valente and R. F. S. Menna-Barreto, J. Proteomics, 2019, 194, 179-190.

116 F. Montalvao, D. O. Nascimento, M. P. Nunes, C. M. Koeller, A. Morrot, L. M. S. Lery, P. M. Bisch, S. M. R. Teixeira, R. Vasconcellos, L. Freire-de-Lima, M. F. Lopes, N. Heise, G. A. DosReis and C. G. Freire-de-Lima, Front. Immunol., 2018, 9, 671.

117 M. M. Croken, S. C. Nardelli and K. Kim, Trends Parasitol., 2012, 28, 202-213.

118 G. F. Picchi, V. Zulkievicz, M. A. Krieger, N. T. Zanchin, S. Goldenberg and L. M. de Godoy, J. Proteome Res., 2017, 16, 1167-1179.

119 T. C. de Jesus, V. S. Nunes, C. Lopes Mde, D. E. Martil, L. K. Iwai, N. S. Moretti, F. C. Machado, M. L. de Lima-Stein, O. H. Thiemann, M. C. Elias, C. Janzen, S. Schenkman and J. P. da Cunha, J. Proteome Res., 2016, 15, 2039-2051.

120 J. de Oliveira Santos, A. A. Zuma, F. N. de Luna Vitorino, J. P. C. da Cunha, W. de Souza and M. C. M. Motta, Parasitology, 2019, 146, 543-552.

121 C. Ciavaglia Mdo, T. U. de Carvalho and W. de Souza, Biochem. Biophys. Res. Commun., 1993, 193, 718-721. 
122 M. E. Giorgi and R. M. de Lederkremer, Carbohydr. Res., 2011, 346, 1389-1393.

123 J. A. Atwood, 3rd, T. Minning, F. Ludolf, A. Nuccio, D. B. Weatherly, G. Alvarez-Manilla, R. Tarleton and R. Orlando, J. Proteome Res., 2006, 5, 3376-3384.

124 M. J. Alves, R. Kawahara, R. Viner, W. Colli, E. C. Mattos, M. Thaysen-Andersen, M. R. Larsen and G. Palmisano, J. Proteomics, 2017, 151, 182-192.

125 X. Yang and K. Qian, Nat. Rev. Mol. Cell Biol., 2017, 18, 452-465.

126 E. Torres-Gutiérrez, Y. Perez-Cervera, L. Camoin, E. Zenteno, M. O. Aquino-Gil, T. Lefebvre, M. Cabrera-Bravo, O. Reynoso-Ducoing, M. I. Bucio-Torres and P. M. SalazarSchettino, Front. Endocrinol., 2019, 10, 199.

127 H. Hahne, N. Sobotzki, T. Nyberg, D. Helm, V. S. Borodkin, D. M. van Aalten, B. Agnew and B. Kuster, J. Proteome Res., 2013, 12, 927-936.

128 A. Flotho and F. Melchior, Annu. Rev. Biochem., 2013, 82, 357-385.

129 J. C. Bayona, E. S. Nakayasu, M. Laverriere, C. Aguilar, T. J. Sobreira, H. Choi, A. I. Nesvizhskii, I. C. Almeida, J. J. Cazzulo and V. E. Alvarez, Mol. Cell. Proteomics, 2011, 10, M110 007369.

130 I. Bludau and R. Aebersold, Nat. Rev. Mol. Cell Biol., 2020, DOI: 10.1038/s41580-020-0231-2.

131 D. G. Arias, M. D. Pineyro, A. A. Iglesias, S. A. Guerrero and C. Robello, J. Proteomics, 2015, 120, 95-104.

132 L. Piacenza, M. P. Zago, G. Peluffo, M. N. Alvarez, M. A. Basombrio and R. Radi, Int. J. Parasitol., 2009, 39, 1455-1464.

133 L. Piacenza, G. Peluffo, M. N. Alvarez, J. M. Kelly, S. R. Wilkinson and R. Radi, Biochem. J., 2008, 410, 359-368.

134 M. P. Zago, Y. M. Hosakote, S. J. Koo, M. Dhiman, M. D. Pineyro, A. Parodi-Talice, M. A. Basombrio, C. Robello and N. J. Garg, Infect. Immun., 2016, 84, 1842-1856.

135 A. Trochine, G. Alvarez, S. Corre, P. Faral-Tello, R. Duran, C. I. Batthyany, H. Cerecetto, M. Gonzalez and C. Robello, Exp. Parasitol., 2014, 140, 33-38.

136 B. S. Hall and S. R. Wilkinson, Antimicrob. Agents Chemother., 2012, 56, 115-123.

137 F. Diaz-Viraque, M. L. Chiribao, A. Trochine, F. GonzalezHerrera, C. Castillo, A. Liempi, U. Kemmerling, J. D. Maya and C. Robello, Front. Immunol., 2018, 9, 456.

138 G. V. Brunoro, V. M. Faca, M. A. Caminha, A. T. Ferreira, M. Trugilho, K. C. de Moura, J. Perales, R. H. Valente and R. F. Menna-Barreto, PLoS Neglected Trop. Dis., 2016, 10, e0004951.

139 G. A. L. Vieira, M. Silva, L. O. Regasini, F. Cotinguiba, H. J. Laure, J. C. Rosa, M. Furlan and R. M. B. Cicarelli, Braz. J. Infect. Dis., 2018, 22, 208-218.

140 A. J. Roberts, L. S. Torrie, S. Wyllie and A. H. Fairlamb, Biochem. J., 2014, 459, 323-332.

141 A. J. Roberts and A. H. Fairlamb, Sci. Rep., 2016, 6, 31078.

142 P. Buscher, G. Cecchi, V. Jamonneau and G. Priotto, Lancet, 2017, 390, 2397-2409.

143 J. R. Franco, P. P. Simarro, A. Diarra and J. G. Jannin, Clin. Epidemiol., 2014, 6, 257-275.
144 S. Mogk, A. Meiwes, S. Shtopel, U. Schraermeyer, M. Lazarus, B. Kubata, H. Wolburg and M. Duszenko, PLoS One, 2014, 9, e91372.

145 S. Mogk, A. Meiwes, C. M. Bosselmann, H. Wolburg and M. Duszenko, Trends Parasitol., 2014, 30, 470-477.

146 A. H. Fairlamb, Trends Parasitol., 2003, 19, 488-494.

147 A. H. Fairlamb, Drugs Today, 2019, 55, 705-712.

148 A. H. Fairlamb and D. Horn, Trends Parasitol., 2018, 34, 481-492.

149 M. D. Urbaniak, M. L. Guther and M. A. Ferguson, PLoS One, 2012, 7, e36619.

150 M. Dejung, I. Subota, F. Bucerius, G. Dindar, A. Freiwald, M. Engstler, M. Boshart, F. Butter and C. J. Janzen, PLoS Pathog., 2016, 12, e1005439.

151 M. M. Shimogawa, E. A. Saada, A. A. Vashisht, W. D. Barshop, J. A. Wohlschlegel and K. L. Hill, Mol. Cell. Proteomics, 2015, 14, 1977-1988.

152 M. Tinti, M. L. S. Guther, T. W. M. Crozier, A. I. Lamond and M. A. J. Ferguson, Wellcome Open Res., 2019, 4, 152.

153 F. Butter, F. Bucerius, M. Michel, Z. Cicova, M. Mann and C. J. Janzen, Mol. Cell. Proteomics, 2013, 12, 172-179.

154 K. Gunasekera, D. Wuthrich, S. Braga-Lagache, M. Heller and T. Ochsenreiter, BMC Genomics, 2012, 13, 556.

155 D. Horn, Mol. Biochem. Parasitol., 2014, 195, 123-129.

156 C. J. Merrick and M. T. Duraisingh, Mol. Microbiol., 2006, 62, 612-620.

157 H. Reis, M. Schwebs, S. Dietz, C. J. Janzen and F. Butter, Nucleic Acids Res., 2018, 46, 2820-2833.

158 T. K. Smith, F. Bringaud, D. P. Nolan and L. M. Figueiredo, F1000Research, 2017, 6, F1000 Faculty Rev-683.

159 C. Goos, M. Dejung, C. J. Janzen, F. Butter and S. Kramer, PLoS One, 2017, 12, e0181884.

160 K. M. Tyler, A. Fridberg, K. M. Toriello, C. L. Olson, J. A. Cieslak, T. L. Hazlett and D. M. Engman, J. Cell Sci., 2009, 122, 859-866.

161 A. I. Sharma, C. L. Olson and D. M. Engman, Pathogens, 2017, 6, E39.

162 A. R. Siafakas, L. C. Wright, T. C. Sorrell and J. T. Djordjevic, Eukaryotic Cell, 2006, 5, 488-498.

163 C. P. Ooi, B. Rotureau, S. Gribaldo, C. Georgikou, D. Julkowska, T. Blisnick, S. Perrot, I. Subota and P. Bastin, PLoS One, 2015, 10, e0133676.

164 J. C. Munday, A. A. Eze, N. Baker, L. Glover, C. Clucas, D. Aguinaga Andres, M. J. Natto, I. A. Teka, J. McDonald, R. S. Lee, F. E. Graf, P. Ludin, R. J. Burchmore, C. M. Turner, A. Tait, A. MacLeod, P. Maser, M. P. Barrett, D. Horn and H. P. De Koning, J. Antimicrob. Chemother., 2014, 69, 651-663.

165 J. D. Unciti-Broceta, J. L. Arias, J. Maceira, M. Soriano, M. Ortiz-Gonzalez, J. Hernandez-Quero, M. Munoz-Torres, H. P. de Koning, S. Magez and J. A. Garcia-Salcedo, PLoS Pathog., 2015, 11, e1004942.

166 N. J. Temperton, S. R. Wilkinson, D. J. Meyer and J. M. Kelly, Mol. Biochem. Parasitol., 1998, 96, 167-176.

167 N. G. Kolev, J. B. Franklin, S. Carmi, H. Shi, S. Michaeli and C. Tschudi, PLoS Pathog., 2010, 6, e1001090. 
168 T. W. M. Crozier, M. Tinti, R. J. Wheeler, T. Ly, M. A. J. Ferguson and A. I. Lamond, Mol. Cell. Proteomics, 2018, 17, 1184-1195.

169 J. Bonnet, C. Garcia, T. Leger, M. P. Couquet, P. Vignoles, G. Vatunga, J. Ndung'u, C. Boudot, S. Bisser and B. Courtioux, J. Proteomics, 2019, 196, 150-161.

170 T. Teesalu, A. Kulla, A. Simisker, V. Siren, D. A. Lawrence, T. Asser and A. Vaheri, Thromb. Haemostasis, 2004, 92, 358-368.

171 M. Uhlen, L. Fagerberg, B. M. Hallstrom, C. Lindskog, P. Oksvold, A. Mardinoglu, A. Sivertsson, C. Kampf, E. Sjostedt, A. Asplund, I. Olsson, K. Edlund, E. Lundberg, S. Navani, C. A. Szigyarto, J. Odeberg, D. Djureinovic, J. O. Takanen, S. Hober, T. Alm, P. H. Edqvist, H. Berling, H. Tegel, J. Mulder, J. Rockberg, P. Nilsson, J. M. Schwenk, M. Hamsten, K. von Feilitzen, M. Forsberg, L. Persson, F. Johansson, M. Zwahlen, G. von Heijne, J. Nielsen and F. Ponten, Science, 2015, 347, 1260419.

172 O. V. Nikolskaia, Y. V. Kim, O. Kovbasnjuk, K. J. Kim and D. J. Grab, Int. J. Parasitol., 2006, 36, 513-519.

173 H. M. Kariithi, S. Boeren, E. K. Murungi, J. M. Vlak and A. M. Abd-Alla, Parasites Vectors, 2016, 9, 424.

174 J. Van Den Abbeele, G. Caljon, K. De Ridder, P. De Baetselier and M. Coosemans, PLoS Pathog., 2010, 6, e1000926.

175 S. B. Ogueta, G. C. Macintosh and M. T. Tellez-Inon, J. Eukaryotic Microbiol., 1998, 45, 392-396.

176 S. Chaubey, M. Grover and U. Tatu, J. Biol. Chem., 2014, 289, 16662-16674.

177 J. S. Seeler and A. Dejean, Nat. Rev. Mol. Cell Biol., 2003, 4, 690-699.

178 M. Engstler, T. Pfohl, S. Herminghaus, M. Boshart, G. Wiegertjes, N. Heddergott and P. Overath, Cell, 2007, 131, 505-515.

179 C. Gadelha, W. Zhang, J. W. Chamberlain, B. T. Chait, B. Wickstead and M. C. Field, Mol. Cell. Proteomics, 2015, 14, 1911-1926.

180 L. Kohl, D. Robinson and P. Bastin, EMBO J., 2003, 22, 5336-5346.

181 I. Subota, D. Julkowska, L. Vincensini, N. Reeg, J. Buisson, T. Blisnick, D. Huet, S. Perrot, J. Santi-Rocca, M. Duchateau, V. Hourdel, J. C. Rousselle, N. Cayet, A. Namane, J. Chamot-Rooke and P. Bastin, Mol. Cell. Proteomics, 2014, 13, 1769-1786.

182 W. Basu Ball, J. K. Neff and V. M. Gohil, FEBS Lett., 2018, 592, 1273-1290.

183 H. F. Tian, J. M. Feng and J. F. Wen, BMC Evol. Biol., 2012, 12, 32.

184 D. Schadeli, M. Serricchio, H. Ben Hamidane, A. Loffreda, A. Hemphill, T. Beneke, E. Gluenz, J. Graumann and P. Butikofer, FASEB J., 2019, 33, 13161-13175.

185 M. D. Urbaniak, D. M. Martin and M. A. Ferguson, J. Proteome Res., 2013, 12, 2233-2244.
186 I. R. Nett, L. Davidson, D. Lamont and M. A. Ferguson, Eukaryotic Cell, 2009, 8, 617-626.

187 I. R. Nett, D. M. Martin, D. Miranda-Saavedra, D. Lamont, J. D. Barber, A. Mehlert and M. A. Ferguson, Mol. Cell. Proteomics, 2009, 8, 1527-1538.

188 N. F. Wilson and P. A. Lefebvre, Eukaryotic Cell, 2004, 3, 1307-1319.

189 R. T. Jacobs, B. Nare, S. A. Wring, M. D. Orr, D. Chen, J. M. Sligar, M. X. Jenks, R. A. Noe, T. S. Bowling, L. T. Mercer, C. Rewerts, E. Gaukel, J. Owens, R. Parham, R. Randolph, B. Beaudet, C. J. Bacchi, N. Yarlett, J. J. Plattner, Y. Freund, C. Ding, T. Akama, Y. K. Zhang, R. Brun, M. Kaiser, I. Scandale and R. Don, PLoS Neglected Trop. Dis., 2011, 5, e1151.

190 D. C. Jones, B. J. Foth, M. D. Urbaniak, S. Patterson, H. B. Ong, M. Berriman and A. H. Fairlamb, PLoS Neglected Trop. Dis., 2015, 9, e0004299.

191 J. A. Frearson, S. Brand, S. P. McElroy, L. A. Cleghorn, O. Smid, L. Stojanovski, H. P. Price, M. L. Guther, L. S. Torrie, D. A. Robinson, I. Hallyburton, C. P. Mpamhanga, J. A. Brannigan, A. J. Wilkinson, M. Hodgkinson, R. Hui, W. Qiu, O. G. Raimi, D. M. van Aalten, R. Brenk, I. H. Gilbert, K. D. Read, A. H. Fairlamb, M. A. Ferguson, D. F. Smith and P. G. Wyatt, Nature, 2010, 464, 728-732.

192 H. P. Price, M. R. Hodgkinson, M. H. Wright, E. W. Tate, B. A. Smith, M. Carrington, M. Stark and D. F. Smith, Biochim. Biophys. Acta, 2012, 1823, 1178-1191.

193 M. H. Wright, D. Paape, H. P. Price, D. F. Smith and E. W. Tate, ACS Infect. Dis., 2016, 2, 427-441.

194 M. Berriman, E. Ghedin, C. Hertz-Fowler, G. Blandin, H. Renauld, D. C. Bartholomeu, N. J. Lennard, E. Caler, N. E. Hamlin, B. Haas, U. Bohme, L. Hannick, M. A. Aslett, J. Shallom, L. Marcello, L. Hou, B. Wickstead, U. C. Alsmark, C. Arrowsmith, R. J. Atkin, A. J. Barron, F. Bringaud, K. Brooks, M. Carrington, I. Cherevach, T. J. Chillingworth, C. Churcher, L. N. Clark, C. H. Corton, A. Cronin, R. M. Davies, J. Doggett, A. Djikeng, T. Feldblyum, M. C. Field, A. Fraser, I. Goodhead, Z. Hance, D. Harper, B. R. Harris, H. Hauser, J. Hostetler, A. Ivens, K. Jagels, D. Johnson, J. Johnson, K. Jones, A. X. Kerhornou, H. Koo, N. Larke, S. Landfear, C. Larkin, V. Leech, A. Line, A. Lord, A. Macleod, P. J. Mooney, S. Moule, D. M. Martin, G. W. Morgan, K. Mungall, H. Norbertczak, D. Ormond, G. Pai, C. S. Peacock, J. Peterson, M. A. Quail, E. Rabbinowitsch, M. A. Rajandream, C. Reitter, S. L. Salzberg, M. Sanders, S. Schobel, S. Sharp, M. Simmonds, A. J. Simpson, L. Tallon, C. M. Turner, A. Tait, A. R. Tivey, S. Van Aken, D. Walker, D. Wanless, S. Wang, B. White, O. White, S. Whitehead, J. Woodward, J. Wortman, M. D. Adams, T. M. Embley, K. Gull, E. Ullu, J. D. Barry, A. H. Fairlamb, F. Opperdoes, B. G. Barrell, J. E. Donelson, N. Hall, C. M. Fraser, S. E. Melville and N. M. El-Sayed, Science, 2005, 309, 416-422.

195 C. Tiengwe, L. Marcello, H. Farr, C. Gadelha, R. Burchmore, J. D. Barry, S. D. Bell and R. McCulloch, PLoS One, 2012, 7, e32674. 